\title{
Enforcement against Organized Crime Fosters Illegal Markets: Evidence from the Yakuza*
}

\author{
Tetsuya Hoshino $\quad$ Takuma Kamada ${ }^{\ddagger}$
}

August, 2020

\begin{abstract}
The Yakuza Exclusion Ordinances (YEOs) have been implemented at different times across prefectures in Japan, where it is not illegal to organize or join criminal organizations - the yakuza. The YEOs indirectly regulate on the yakuza by prohibiting non-yakuza citizens from providing any benefit to them. In Japan, organized fraud has been a serious issue, accounting for almost half of the total financial damage by all property crimes. Difference-in-differences estimates indicate that (i) the YEOs increase the revenue from organized fraud and (ii) the YEOs' effects are greater in regions with lower concentration levels of yakuza syndicates. Additional evidence suggests that both current and former yakuza members engage in the fraud in the presence of the YEOs. One policy implication is that the rehabilitation assistance for former yakuza members can be effectively implemented in regions with lower concentration of yakuza syndicates.
\end{abstract}

Keywords: Enforcement; Organized crime; Yakuza; Illegal markets.

JEL codes: K4, K14, K42.

\footnotetext{
* Names in alphabetical order; we contributed equally to this study. We thank Yu Awaya, Daniel DellaPosta, Corina Graif, Noboru Hirosue, Akira Igarashi, Hirokazu Ishise, Hajime Katayama, Hanae Katayama, Kohei Kawaguchi, Shuhei Kitamura, Yoshiki Kobayashi, Miki Kohara, Thomas A. Loughran, Tetsuya Matsubayashi, Yutaka Maeda, Takeshi Murooka, Mark Moore, Jun Nakabayashi, Kentaro Nakajima, Holly Nguyen, Yoko Okuyama, Wayne Osgood, Brian Phillips, Barry Ruback, Peter Reuter, Tomoyori Saito, Yoshimichi Sato, Masayuki Sawada, Stephanie M. Scott, Nobuo Suzuki, Katsuya Takii, Mari Tanaka, Christopher Winship, Letian Zhang, and the participants at the 38th Annual APPAM Fall Research Conference, Osaka University, Pennsylvania State University, and Tohoku University for their helpful comments and discussion. We are grateful to the National Police Agency and Prefectural Police Departments for providing data on the yakuza and organized fraud. Kamada would like to thank Grant-in-Aid from the Japan Society for the Promotion of Science Fellows (26-5010). The usual disclaimer applies.

${ }^{\dagger}$ Department of Economics, ITAM. Email: tetsuya.hoshino@itam.mx

${ }^{\ddagger}$ Corresponding author. Osaka School of International Public Policy, Osaka University. Email: kamada@osipp.osaka-u.ac.jp
} 
Were the Yamaguchi-gumi broken up now, the public order would become much worse.

... Young members would be destitute. ... [W]ithout our discipline, they would do as they like. ... [T]hey would be driven to income-generating crimes.

Shinobu Tsukasa, the leader of the Yamaguchi-gumi ${ }^{1}$

\section{Introduction}

Does enforcement against organized crime syndicates deter illegal activities? It may deter them effectively, since it increases the cost of the illegal activities. However, it could be even counterproductive because it stimulates competition or conflict within or between criminal organizations. The existing literature has provided mixed evidence. On the one hand, focused deterrence strategies, which identify a small number of active gang members responsible for perpetuating violence and give them deterrence messages and sanctions against them, are shown to be effective in reducing gang-related violence (Braga et al., 2001, 2014; Piehl et al., 2003). On the other hand, countermeasures, such as the leadership removal of criminal organizations and troop deployment, increase violence, especially in the context of Latin America (Calderón et al., 2015; Dell, 2015; Dickenson, 2014; Lindo and Padilla-Romo, 2018).

In this paper, we study a novel kind of intervention, which falls into third-party policing in the criminology literature. Third-party policing is an indirect intervention that refers to police efforts to persuade or coerce third parties - for instance, non-offending individuals who the police believe influence those participating in the target crime - to take some responsibility for crime control and prevention (Buerger and Mazerolle, 1998; Mazerolle and Ransley, 2006). It is suggested that this approach is effective in reducing the size of criminal organizations - the yakuza - in Japan (Hoshino and Kamada, 2020). ${ }^{2}$ In spite of this effect, the present paper studies the possibility that this kind of intervention results in the proliferation of illegal markets because it may cripple existing (legal and illegal) economic opportunities of the criminal organizations.

Japan has recently introduced the Yakuza Exclusion Ordinances (YEOs), which aim to prevent non-yakuza citizens and companies from associating with the yakuza, rather than toughens direct regulations on the yakuza themselves. The yakuza's economic activities are based on relationship with non-yakuza citizens and companies (henceforth, non-yakuza). The yakuza have both legal and illegal income sources - for instance, extortion, protection rackets, interference in civil disputes, and the construction of public works. The YEOs prohibit non-yakuza from providing benefit that may help yakuza activities. For example, the YEOs ban non-yakuza from receiving extra-state protection by the yakuza, serving food and drink, renting offices, and providing insurance to them. Non-yakuza may be subject to penalties if they violate the YEOs. As Figure 1 shows, the number of yakuza members sharply declined after the YEOs' enactment. Hoshino and Kamada (2020) estimate that the YEOs account for approximately $26 \%$ of the recent reduction of yakuza members.

\footnotetext{
${ }^{1}$ In an interview with a Japanese newspaper (Sankei Shimbun, 2011).

${ }^{2}$ Here, "yakuza" is used as a general term referring to Japanese criminal organizations or their members.
} 
Figure 1: Change in Number of Yakuza Members Over Time

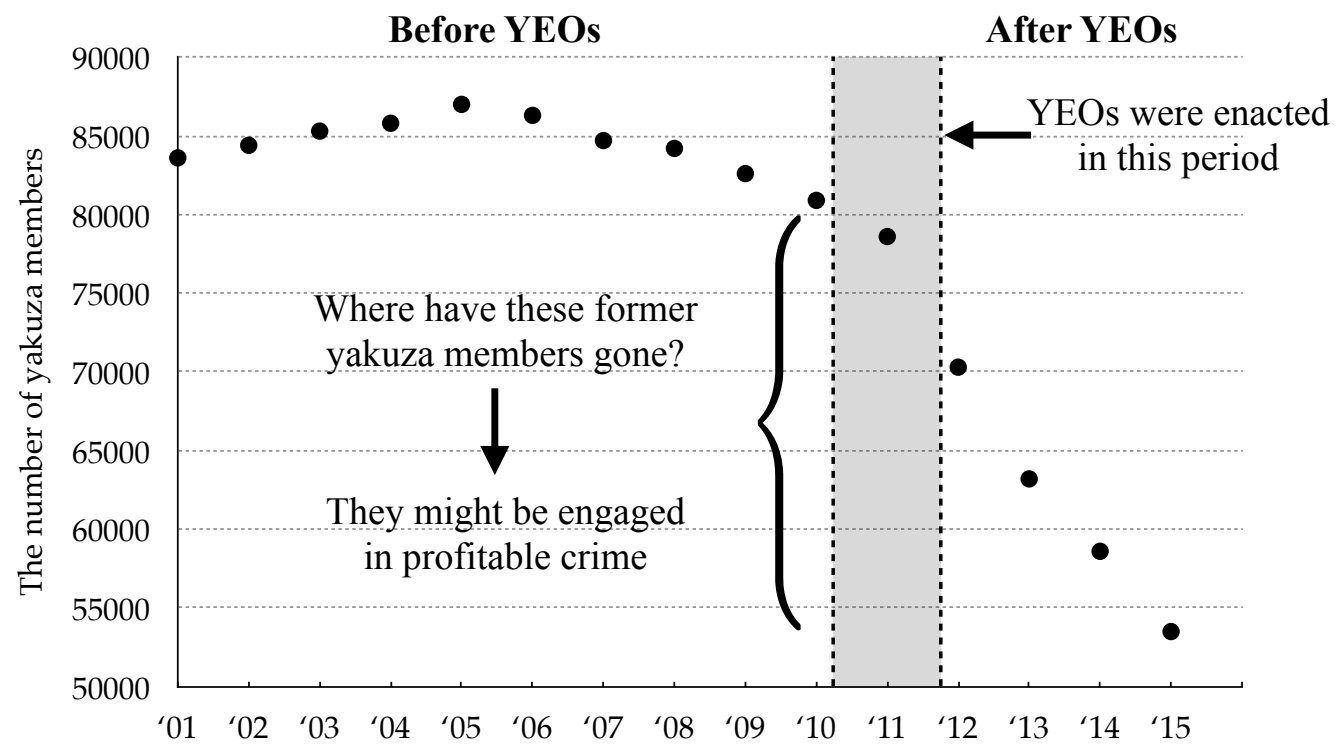

Notes: The YEOs were enacted in the shaded period. Since they are prefecture-level local ordinances, the enactment dates vary from prefecture to prefecture. Prefectures form the first level of jurisdiction and administrative division, and Japan consists of forty-seven prefectures.

The purpose of the present paper is to study unintended, collateral consequences of the YEOs. We argue that the decrease in the number of yakuza members does not necessarily improve the public safety. The intuition behind is as follows. The number of yakuza members has decreased, which necessarily increases the number of former yakuza members. How do these former yakuza members make a living? Many of them are poor and have difficulty in finding legitimate jobs because of their yakuza histories. Indeed, only 1-2 percent of former yakuza members could find legitimate jobs between 2010 and 2013 according to the National Center for the Removal of Criminal Organizations (Hirosue, 2016). The limited economic opportunities available to the former yakuza members decrease the relative costs of committing crimes. Moreover, current yakuza members also might have started a new kind of crime to earn money because the YEOs have crippled their existing economic opportunities. Hence, the YEOs might have increased in crimes from which both current and former yakuza members can make money.

We argue that they may have switched over to organized fraud under the YEOs. Organized crime has been diversified, including not only violent crime, which are often associated with drug trafficking, but also "brain crime." The motivation to examine the organized fraud is two-fold. First, the organized fraud has been a serious issue in Japan, such that the related financial damage accounts for almost half of the total financial damage caused by all kinds of property crimes (National Police Agency, 2012, 2014b). The financial damage of the organized fraud per case has increased by $85 \%$ from 2011 to 2013, the period that our data on the fraud covers. Most of this kind of fraud uses telecommunications - for instance, phones, invoices, and emails - to acquire money 
illegally, often called communications fraud. Second, the fraud is considered to be an emergent revenue for today's yakuza (National Police Agency, 2015); moreover, there is a journalistic account indicating that former yakuza members organize fraud groups, mostly with non-yakuza gangs, to commit organizational fraud (NHK, 2014).

Our focus on the organized fraud, a property crime, is in contrast to the majority of existing studies on interventions against criminal organizations (e.g., Dell, 2015; Lindo and Padilla-Romo, 2018; Piehl et al., 2003). These existing studies focus on violence to understand the shift in their crime activities, but we point out that violent crime, including murder, robbery, and extortion, may not be well-paid crime in Japan, in which the crime-arrest ratio for those types of crime is very high ranging from 80 to early 100\%. Furthermore, yakuza's economic activities have become more extensive in a way that does not necessarily resort to violence, which minimizes the cost associated with threat and violence. Given this recent trend, it is important to study such a "brain crime" aspect of organized crime.

To estimate the YEOs' unintended consequences, we take a difference-in-differences (DiD) strategy, exploiting monthly variation in the enactment dates of the YEOs across regions. We also take into account the possibility that the YEOs' effects depend on the extent of potential regional conflict and competition between yakuza syndicates. To this end, we construct a regional concentration index of yakuza syndicates, which we call yakuza concentration index (YCI). Using this design, we estimate (i) the YEOs' effect on organized fraud and (ii) the heterogeneity of the YEOs' effects by YCI.

Our main findings are two-folds. First, we find that the YEOs increase the revenue generated by the organized fraud. Our estimates suggest that the YEOs account for nearly $40 \%$ of a recent increase in the organized fraud. Second, the the YEOs effects on the revenue of the organized fraud are smaller in regions with higher concentration levels of yakuza syndicates in terms of YCI. Our main results survive a variety of robustness checks, including falsification tests using lead treatment indicators in the form of an event-study framework, permutation tests, as well as other specification tests.

Why are the YEOs effects smaller in areas with higher yakuza concentration? We interpret this result as a natural consequence of strategic interaction between yakuza syndicates. In less yakuza concentrated areas, a yakuza syndicate is less likely to be involved in competition or conflict with its rival syndicates and thus has less incentives to maintain its members. In contrast, a yakuza syndicate is more willing to keep its members if it has many rival syndicates. Hence, more yakuza members should leave their syndicates in less yakuza concentrated areas in the presence of the YEOs. Along the line of this interpretation, the YEOs decreased the more number of yakuza members in areas with lower YCI (Hoshino and Kamada, 2020). Hence, there should be more former yakuza members in areas with lower yakuza concentration. Since they have scarce lawful economic opportunities and thus may be driven to income-generating crime, we argue that the financial damage of the organized fraud should increase more in such areas. Appendix B provides indirect and suggestive evidence that other channels such as the demand for illegal markets, level 
of enforcement, different economic conditions do not explain the heterogeneous effect by YCI.

We then study two possible channels through which the YEOs may affect the organized fraud. First, former yakuza members may engage in the organized fraud, as argued above. Using the change in the number of yakuza members as a proxy for former yakuza members, we provide empirical evidence suggesting that the cumulative change in the number of yakuza members is negatively correlated with the revenue of the organized fraud, and this effect is smaller in areas with lower YCI. Second, current yakuza members may also engage in the fraud, since the YEOs deprive them of their traditional income sources. Using arrest data of yakuza members in Tokyo, we find that the YEOs increase the number of arrests of yakuza members for fraud. Since arrest data may reflect unobserved levels of enforcement, it is less clear whether this increase is due to a change in behaviors of yakuza members, or a change in behavior of police officers. We use other types of crime such as violent crime as placebo outcomes, and we show that the YEOs only increase arrests for fraud but not other types of crime.

We draw two policy implications from our empirical findings. First, while the YEOs reduce the number of yakuza members, this study reveals that the YEOs increase the organized fraud. It is, therefore, suggested that rehabilitation assistance to former yakuza members would be important for the public's safety. Second, the rehabilitation assistance may be effectively implemented in regions with lower, rather than higher, concentration of yakuza syndicates. More specifically, the effectiveness may depend on strategic relations between organized crime syndicates. When criminal organizations are in competition (for control over illegal markets), it may be a powerful tool to leverage the competition. That is, it may be more effective to attack a few criminal organizations intensively rather than many. The reason is that as one criminal organization becomes weaker, others will make less effort to maintain their power.

This study speaks to several strands of the literature. First, the literature on enforcement against organized crime generally focuses on direct interventions where law enforcement officers play a primary role (Piehl et al., 2003; Dell, 2015). In contrast, our policy experiment is an indirect intervention. To the best of our knowledge, there are two empirical studies on indirect interventions against organized crime. Grogger (2002) studies the effect of gang civil injunction on gang-related violence, finding a reduction in violence. In the context of the yakuza, Hoshino and Kamada (2020) provide evidence suggesting that the YEOs reduce the number of yakuza members, especially in regions with lower yakuza concentration.

Second, most existing studies on interventions against organized crime focuses on violence to understand the shifts in the activities of criminal organizations, especially in the context of drugrelated crime in Latin America (e.g., Calderón et al., 2015; Dell, 2015; Lindo and Padilla-Romo, 2018). In contrast, we study the economy of organized crime. This approach is of interest because existing evidence on the engagement of criminal organizations in predatory forms of incomegenerating crime is mixed (Levi and Maguire, 2004), and the effect on the economy of organized crime is not well understood in the literature.

Lastly, the seminal work by Becker (1968) predicts that the participation in illegal activities 
depends on the accessibility to legal economic opportunities. Dell et al. (2019) find that a decline in manufacturing job opportunities caused by global trade with China increases drug-related violence. They argue that the lower (legal) market opportunities (relatively) enriched the illegal market opportunities, which results in the increase in violence. We can interpret their result as a consequence of increasing the participants in criminal organizations. Meanwhile, our argument is that lowering the yakuza's market opportunities (by the YEOs) ended up inducing even former yakuza members, who defect from their syndicates because of the YEOs, to commit crime. That is, an intervention increases the incentive to exist from a criminal organization, but because it cripples existing (legal and illegal) economic opportunities, it also results in the proliferation of illegal markets. Therefore, our focus is on the unintended side-effect caused by an intervention against organized crime.

The rest of this paper is organized as follows. Section 2 provides the background knowledge of the yakuza. Section 3 describes our data and identification strategy. Section 4 provides our main results, and Section 5 examines two potential channels. Section 6 concludes.

\section{Yakuza Exclusion Ordinances}

\subsection{Background on the Yakuza}

We provide background information about the yakuza that is necessary to understand our research design. This review is not comprehensive. For a more comprehensive review, see, for example, Hill (2003, 2004).

Yakuza Syndicates. It is not illegal to organize or join yakuza syndicates in Japan due to the Freedom of Association (the Constitution of Japan, Article 21). This is a sharp distinction between Japan and many other countries in which it is illegal to organize or join crime syndicates. It is true that the yakuza traditionally have been socially tolerated in Japan, at least to some extent, but the recent victimization of non-yakuza by the yakuza have led the government to tighten its restrictions on the yakuza.

One of the regulations is the Anti-Yakuza Laws (Bōryokudan Taisaku Hō), enacted in 1992. Under these laws, 21 yakuza syndicates are "designated" according to several criteria during the period of this study. The criteria for the designation are: (i) the yakuza syndicate has a hierarchical organizational structure; (ii) its members use violence to make money; and (iii) its members have criminal records. As of 2009 (before the YEOs), there were 82,600 yakuza members in total, and approximately $96 \%$ of them belonged to one of the designated yakuza syndicates. This percentage did not change over the period examined in our study (National Police Agency, 2009, 2014a). Moreover, data on the yakuza syndicates are usually restricted to the designated ones. Hence, we focus on the designated yakuza syndicates and refer to them simply as yakuza. ${ }^{3}$

\footnotetext{
${ }^{3}$ There used to be 22 designated yakuza syndicates, but in 2011,2 of them, both of which operated only in Okinawa, merged.
} 
Economic Activities of the Yakuza. There are several strands of economic activities - legal or illegal - that the yakuza engage in. Among the illegal economic activities, the yakuza's main traditional income sources are as follows: extortion, the distribution of methamphetamine, gambling, and illegal bookmaking (National Police Agency, 2009). However, the yakuza's economic activitieslegal or illegal — vary according to the social landscape and time period. The yakuza's contemporary economic activities are more diverse than their past activities (National Police Agency, 2015).

Ever since the Japanese economic boom in the 1950s, the yakuza have been engaged in protection racketeering to make money illegally (mikajimeryō) from business entities such as the sex industry. They have also made money illegally from gambling and extortion. Since the economic boom, the yakuza have had an enormous influence over the Japanese infrastructure and construction sectors. The yakuza's economic activity grew in the 1970s and 1980s, and since then, the yakuza have been referred to as the economic yakuza (Hill, 2003, 2004). For instance, they have benefited from lending money at illegally high interest rates and from serving as corporate blackmailers (sōkaiya) who abuse the rights of stakeholders to extort money. They have also interfered with civil disputes $(\min b \bar{o})$. Since official legal processes are often slow and costly, some non-yakuza have chosen to have the yakuza resolve their problems (Milhaupt and West, 2000). The yakuza also targeted the construction of nuclear reactors. Nuclear reactors entail large site-specific investments, offering the yakuza a lucrative target. The level of extortion increases when a utility announces plans to build a reactor (Ramseyer, 2016). Behind all of these activities is the threat of violence.

In more recent years, however, as the enforcement on the yakuza has increased, the use and threat of violence have become less common, and accordingly, the yakuza's income sources have changed (National Police Agency, 2015). The yakuza have started running (legal) front companies, which reduces the costs of using violence, such as arrest and incarceration. Moreover, they also have expanded their involvement in illegal activities that do not rely on violence - in particular, organized fraud that we describe in greater detail below.

\subsection{Organized Fraud}

We examine unintended effects that the YEOs enactment might have had on organized fraud. The focus on organized fraud is of great interest. We expand on this crime, with emphasis on its financial damage on the society as well as on the incentives for why current and former yakuza members engage in the crime under the YEOs.

In Japan, the organized fraud mainly corresponds to fraud that uses telecommunications-for instance, phones, invoices, and emails - to acquire money illegally, often called communications fraud. This kind of fraud is organized and committed by groups of fraudsters. It usually targets the elderly - nearly $80 \%$ of the victims are above 60 years old (National Police Agency, 2014b). In a typical scenario, the fraudsters (not necessarily yakuza members) pretend as if they were children or grandchildren of the (elderly) victims and attempt to panic the victims by saying that they get in trouble, such as an accident, and need to pay money as soon as possible, to ask the victims to send money. This kind of fraud has been doing serious damages for the recent 15 years in Japan. 
Figure 2: Organization Chart of Organized Fraud Groups

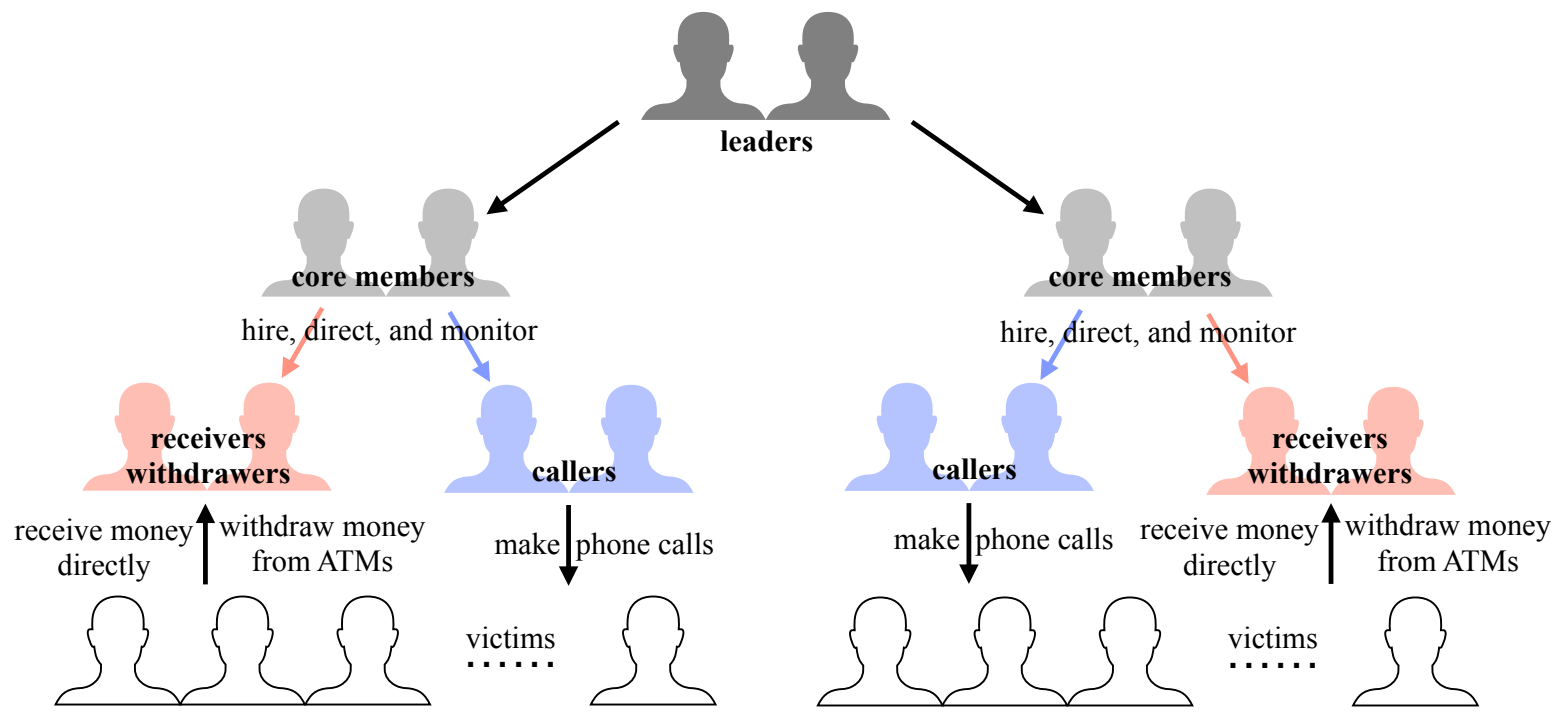

Notes: Organized fraud groups have hierarchical structures. Yakuza members, current or former, occupy the midor high-level positions. They hire, direct, and monitor the lower level members. The low-end members have different roles - callers, receivers, and withdrawers. They are faced with the highest risk of apprehension.

In 2014, the total financial damage amounted to 56 billion yen (equivalent to approximately 530 million dollars), which accounted for nearly half of the total financial damage caused by property crimes in Japan (National Police Agency, 2014b).

The organized fraud is committed by fraudster groups with hierarchical structures, typically consisting of three layers (Figure 2). Top-level leaders have power beneath the middle layer of core members, and the core members hire and direct a low-end members. The low-end members consists of multiple members, and they have different roles. Callers (kakeko) make fraud phone calls, receivers (ukeko) visit victims to directly receive money from them, and withdrawers (dashiko) withdraw money that victims deposit from ATM. Regardless of their roles, the low-end members dirty their hands and thus are faced with the highest risk of apprehension. Yakuza members, current or former, do not do the low-end jobs, but they, as higher-level members, hire and instruct low-end members, thereby avoiding the risk of apprehension. For instance, nearly $40 \%$ of arrestees who do the high-end job are yakuza members (National Police Agency, 2018). Low-end members are not informed about the details of higher-level members or about the organization itself, and therefore even if they are arrested, the higher-level members are less likely to be exposed by the police.

We point out that organized fraud is a less costly crime, especially for the mid- or high-level members, many of whom are current or former yakuza members, than other types of incomegenerating crime, such as drug trafficking and robbery. Under the Anti-Yakuza Laws, it is difficult and risky for (current) yakuza members to resort to violence, say by exercising the yakuza power, to earn illegal money. It is true that the yakuza may resort to violence to facilitate governance 
Figure 3: YEOs as Third-Party Policing

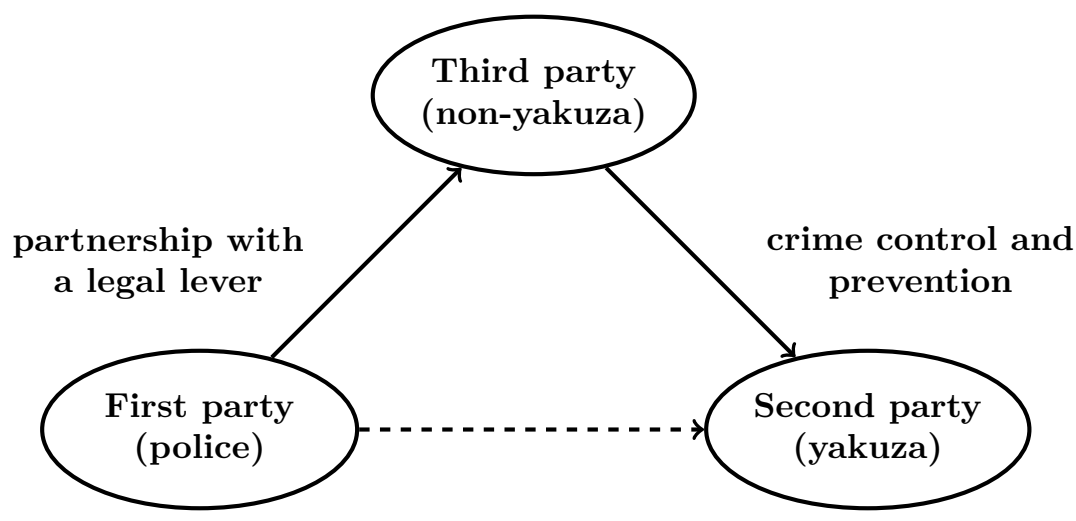

inside their fraud organizations, but violence is not directed to (non-yakuza) victims of the fraud and so the yakuza members are less likely to be accused of. Moreover, the organized fraud is a well-paid also for former yakuza members. Once one defects from a yakuza syndicate, he loses access to yakuza's networks, via which illegal drugs, such as methamphetamine, the most widely abused drug in Japan, is smuggled; therefore, the organized fraud is relatively accessible potential income sources for the former yakuza members. Indeed, both current and former yakuza members are reported to be involved in organized fraud, and it has become an emergent income source for the yakuza (NHK, 2018; National Police Agency, 2014a, 2015).

\subsection{Yakuza Exclusion Ordinances}

To increase enforcement against the yakuza, Japan has recently introduced the Yakuza Exclusion Ordinances (YEOs). ${ }^{4}$ The basic concept behind the YEOs is "society versus the yakuza." This approach makes a contrast to the more traditional approach that is based on the concept of "the police versus the yakuza." In the traditional approach, the police attempt to regulate the yakuza directly, for instance, by severely punishing yakuza members if they commit crimes. In contrast, the YEOs involve non-yakuza individuals and companies in addressing the yakuza problem.

The YEOs fall into third-party policing in the criminology literature. Third-party policing is a policing strategy that relies on resources and institutions other than the police to address crime problems. Specifically, it refers to police efforts to persuade or coerce third parties to take some responsibility for crime control and prevention (Mazerolle and Ransley, 2006). Third-party policing involves three parties - the police, a targeted crime, and a third party. Similarly, the YEOs involve the police, the yakuza as a target, and the non-yakuza as a third party. Figure 3 illustrates the YEOs as a third-party policing strategy.

By prohibiting non-yakuza from providing any benefit to the yakuza, the YEOs aim to eliminate the yakuza's income flow and to weaken the yakuza, thereby helping non-yakuza to live peaceful

\footnotetext{
${ }^{4}$ In 2007, the Minister of Justice announced guidelines to reduce victimization (e.g., citizens, corporations, and governments) by the yakuza. The guidelines emphasize the importance of avoiding associating with the yakuza in any way, given that the association may serve as income sources for the yakuza.
} 
lives as well as soundly develop their business activities. For example, the YEOs ban non-yakuza from receiving extra-state protection by yakuza members. The YEOs also prohibit non-yakuza from renting houses, apartments, or offices to yakuza members and opening bank accounts on their behalf as well as selling insurance to them. Thus, the YEOs attempt to alter the routine behaviors of non-yakuza to eliminate economic opportunities for the yakuza. As previously mentioned, it is not illegal to be a yakuza member in Japan, but the YEOs marginalize the yakuza by prohibiting non-yakuza from associating with them.

While non-yakuza are prohibited from providing benefits that may aid in yakuza activities, they nevertheless may be at a high risk of experiencing retaliation from yakuza members if they comply with the prohibition. This fear of retaliation may tempt the non-yakuza into associating with yakuza members. To aid in implementation, the YEOs impose penalties on non-yakuza if they associate with yakuza members, which may create a dilemma for the non-yakuza. If they comply with the YEOs then they may face retaliation from the yakuza, but otherwise, they might be subject to YEO-imposed penalties. For instance, the authorities may make the names of offending companies public, which will tarnish their reputation and make it difficult for them to transact with banks and other financial institutions. They also could be prohibited from bidding on public construction projects. What is worse, they may be subject to imprisonment and fines.

Here is one example that the authorities used coercive techniques to implement the YEOs. The Onigiri Club is a golf club consisting of 70 construction companies in Fukuoka prefecture. In 2011, it came to light that the managers of nine companies of the Onigiri Club played golf with some yakuza leaders, and the Fukuoka Police Department reported this incident to the local government and made the names of these companies public on its website. Moreover, the local government of Fukuoka expelled these nine companies from public construction projects. As a result, two out of the nine went bankrupt. Such a sanction incentivizes third parties to obey the YEOs.

In general, it is difficult to quantify the actual enforcement levels of the YEOs. We argue, however, that this concern does not pose a serious problem in estimating the YEOs' effects. The National Police Agency reports the number of violators of the YEOs, and these numbers seem to be stable (with a slight increase from 62 to 71) during the period of our study. This by itself suggests that the YEOs are, at least to some extent, well enforced. Of course, it is impossible to show the non-existence of the dark figures of crime. There may be more violators of the YEOs, but the possibility of dark figures does not nullify the effect of the YEOs. If, hypothetically, the YEOs had not been enforced properly and only a few, or even no, non-yakuza had obeyed the YEOs, then the YEOs would have had negligible effects; in other words, the introduction of the YEOs would not change any variables as long as other factors were controlled. Hoshino and Kamada's (2020) empirical finding that the YEOs significantly reduce the number of yakuza members serves as evidence that the YEOs have been well enforced. 


\subsection{Collateral Effects of YEOs}

We argue that the YEOs may result in unintended consequences in that the YEOs increase the revenues of organized fraud. The reduction in yakuza members does not necessarily mean the improvement in the public safety. The decrease in yakuza members necessarily increases former yakuza members. Many of them are poor and have difficulty in finding lawful jobs. Possible reasons include their yakuza histories, in particular tattoos and/or chopped fingers (indicative of the individuals' connection to the yakuza) as well as the lack sufficient human capital. It is difficult for former yakuza members to rehabilitate into (lawful) society.

When former yakuza members engage in organized fraud, they may form or affiliate with other non-yakuza criminal groups that engage in the organized fraud. NHK (2018) interviewed a former yakuza member who was asked to join a non-yakuza criminal group. "I was starving to death [...] [W]hen I heard about the offer [to join the group], I thought I might be able to earn a high income," said he. This suggests that former yakuza members are exposed to criminogenic conditions and associate with non-yakuza criminal peers or other former yakuza peers. It is said that the organized fraud requires sophisticated technical skills (National Police Agency, 2015), and the mentioned non-yakuza groups may serve as an environment in which fraudsters develop crime know-how.

Furthermore, it is possible that current yakuza members are also more likely to engage in new types of crime under the YEOs. Since the YEOs prohibit non-yakuza from providing any economic benefits to yakuza members, non-yakuza are less likely to succumb to extortion by yakuza members. This makes it difficult for the yakuza to squeeze money from non-yakuza in the traditional ways that we reviewed in Section 2.1. Therefore, yakuza members may be motivated to commit crimes in which their connection to the yakuza is less obvious. In fact, yakuza members are reported to be affiliated with non-yakuza criminals to commit organized fraud (National Police Agency, 2018). Therefore, it is possible that by being exposed to different criminogenic environments, current yakuza members obtain criminal skills and information, which, in turn, likely increase the revenue of the organized fraud.

To examine the YEOs' effect, it is important to take into consideration the regional variation in yakuza concentration. We quantify the yakuza concentration by constructing the Yakuza Concentration Index (Section 3.1). As illustrated in Figure 4, the yakuza concentration is regionally clustered, where the darker colored prefectures are exposed to higher concentrations of yakuza syndicates. The YEOs' effect on the organized fraud is potentially related to the yakuza concentration; however, it is not obvious whether the potential synergy between the YEO and the yakuza concentration is positive or negative. On the one hand, the synergy may be positive - i.e., the YEOs'

effect on the fraud may be stronger in more yakuza concentrated regions. This is because, as the fraud is committed organizationally, one may benefit from having more yakuza members around. On the other hand, the synergy may be negative - i.e., the YEOs' effect on the fraud may be weaker in less yakuza concentrated regions. This is because one may be exposed to potential rivals when he has more yakuza members around. 
Figure 4: Prefecture-Level Yakuza Concentration Index

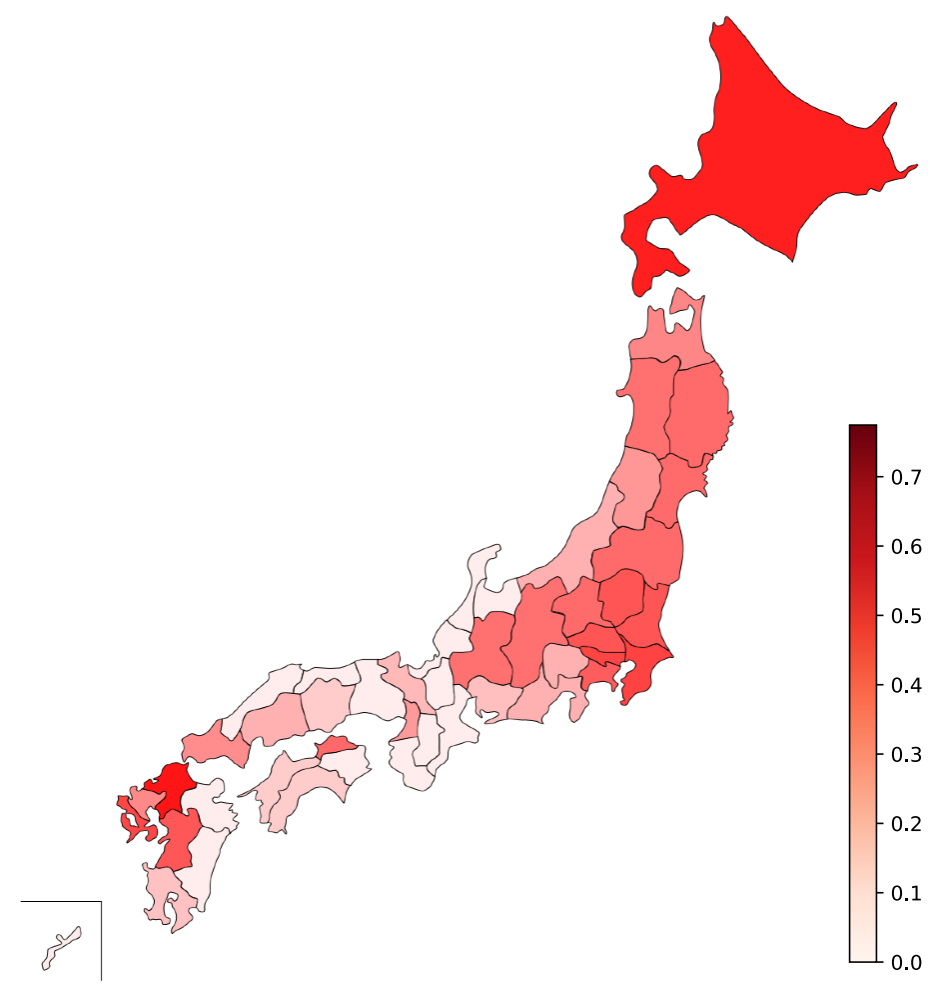

\section{Data and Identification Strategy}

\subsection{Data}

Enactment Dates of YEOs. The YEOs are prefecture-level ordinances. Japan consists of 47 prefectures, and prefectures are the first level of jurisdiction and administrative division. The enactment dates, listed in Table 1, vary across prefectures. ${ }^{5}$ While the majority of prefectures enacted the YEOs in April of 2011, the other prefectures enacted the YEOs between April of 2010 to January of 2012. To identify the effects of YEOs, we exploit the staggered enactment of the YEOs across prefectures, as is discussed in Section 3.2. ${ }^{6}$

\footnotetext{
${ }^{5}$ In several prefectures, the YEOs were amended after their introduction. For example, Akita enacted YEOs in March 2011 and then amended them in July 2011. As we are interested in the TPP-like aspect of the YEOs, we define the enactment date as the date at which the clauses to regulate non-yakuza activity were incorporated. Accordingly, we define the Akita enactment date as July 2011. The YEOs were similarly amended in Tottori, Fukuoka, and Saga.

${ }^{6}$ The contents of the YEOs are slightly different from prefecture to prefecture, but the basic concepts are common across all the prefectures. Under the YEOs, non-yakuza who make contracts are required to check whether the other parties to the contracts are related to yakuza. The relationship that has to be checked differs across prefectures. In a few prefectures, non-yakuza need to check only whether the other parties to contracts are yakuza members. Yet in Tokyo, non-yakuza need to check whether the other parties have been closely associated with the yakuza. This requirement in Tokyo is stringent, but in many other prefectures, non-yakuza are still required to ask the other parties to their contracts if at least five years have passed since they retired from their yakuza syndicates. This rule is often called a five-year rule.
} 
Table 1: Enactment Dates of YEOs

\begin{tabular}{lrr||lll|lll}
\hline Prefecture & \multicolumn{2}{c}{ Enactment } & Prefecture & \multicolumn{2}{c}{ Enactment } & \multicolumn{2}{c}{ Prefecture } & \multicolumn{2}{c}{ Enactment } \\
\hline Hokkaido & Apr. & 2011 & Nagano & Sep. & 2011 & Okayama & Apr. & 2011 \\
Aomori & Jul. & 2011 & Shizuoka & Aug. & 2011 & Hiroshima & Apr. & 2011 \\
Iwate & Jul. & 2011 & Toyama & Aug. & 2011 & Yamaguchi & Apr. & 2011 \\
Miyagi & Apr. & 2011 & Ishikawa & Aug. & 2011 & Tokushima & Apr. & 2011 \\
Akita & Jul. & 2011 & Fukui & Apr. & 2011 & Kagawa & Apr. & 2011 \\
Yamagata & Aug. & 2011 & Gifu & Apr. & 2011 & Ehime & Aug. & 2010 \\
Fukushima & Jul. & 2011 & Aichi & Apr. & 2011 & Kochi & Apr. & 2011 \\
Tokyo & Oct. & 2011 & Mie & Apr. & 2011 & Fukuoka & Apr. & 2010 \\
Ibaraki & Apr. & 2011 & Shiga & Aug. & 2011 & Saga & Jan. & 2012 \\
Tochigi & Apr. & 2011 & Kyoto & Apr. & 2011 & Nagasaki & Apr. & 2010 \\
Gunma & Apr. & 2011 & Osaka & Apr. & 2011 & Kumamoto & Apr. & 2011 \\
Saitama & Aug. & 2011 & Hyogo & Apr. & 2011 & Oita & Apr. & 2011 \\
Chiba & Sep. & 2011 & Nara & Jul. & 2011 & Miyazaki & Aug. & 2011 \\
Kanagawa & Apr. & 2011 & Wakayama & Jul. & 2011 & Kagoshima & Apr. & 2010 \\
Nigata & Aug. & 2011 & Tottori & Apr. & 2011 & Okinawa & Oct. & 2011 \\
Yamanashi & Apr. & 2011 & Shimane & Apr. & 2011 & & & \\
\hline
\end{tabular}

Organized Fraud. We use prefecture-level monthly panel data on organized fraud provided by the NPA, and the data cover the period from 2011 to 2013. Due to this data restriction, the YEOs' treatment dummies are constant in the four prefectures that enacted the YEOs before 2011 (Ehime, Fukuoka, Nagasaki, and Kagoshima). The outcome variable of interest is the revenue of the organized fraud, which is defined as the total financial damage divided by the total number of the organized fraud cases. The revenue of the organized fraud (per case) is, on average, 4 million yen (equivalent to 36,500 dollars), suggesting the profitability of this crime. From 2011 to 2013, the average revenue per case increased from 2.7 million yen to 5 million yen, or by roughly $85 \%$. The number of our observations is 1,613 (47 prefectures $\times 36$ months $=1,692$ less 79 , which we drop when taking the natural logarithm because of zeros).

Yakuza Members. Since the National Police Agency (NPA) reports the number of yakuza members only at the national level, we requested prefecture-level data from the Prefectural Police Departments. We obtained data on 37 out of 47 prefectures from 2008 to 2013. ${ }^{7}$ The provided data contain the number of yakuza members in each of these prefectures. Because the data are yearly panel data, we impute monthly values using linear interpolation. The variable of interest is the yakuza rates, which are defined as the number of yakuza members per 100,000 residents. The average yakuza rate across all the prefectures is 43 .

\footnotetext{
${ }^{7}$ To deal with missing data (about $5 \%$ of the data is missing among the 37 prefectures), we conduct multiple imputations with 10 replications. The results using this variable are combined estimates from the 10 imputations, applying Rubin's rule (Rubin, 1987). Multiple implications rest on the missing-at-random assumption. To indirectly examine this, we conduct a diagnostic test that suggests whether a prefecture provided data on yakuza members does not vary systematically across prefectures conditional on observable covariates included in our model. Therefore, the missing-at-random assumption is likely satisfied conditional on the observed covariates.
} 
According to the Japanese Organized Crime Division of the NPA, the police draw on many sources to identify whether yakuza members have defected from yakuza syndicates. For example, the police consider expulsion letters, interviews with relevant members, and interviews with arrested members. Note that when a member of a syndicate leaves, the syndicate sends an expulsion letter to other syndicates. This prevents the defecting member from transferring to another yakuza syndicate. However, the notification may not be sufficient for the police to count the individual as a yakuza dropout. The police need supporting evidence, which can be obtained through the investigation of yakuza offices and interviews with arrested members. These processes allow the police to track the actual numbers of yakuza members.

We obtained data on the number of yakuza members on 37 out of 47 prefectures from 2008 to 2013 at the yearly level. We define yakuza rates as the number of yakuza members per 100,000 residents. As detailed in Section 5, we use the change in the number of yakuza members as a proxy for the change in the former ones. We use month-level imputed data by linear interpolation.

Yakuza Concentration Index. To construct prefecture-level concentration indices of yakuza syndicates, we use two kinds of data: (i) the number of yakuza syndicates operating in each prefecture; and (ii) the number of members in each yakuza syndicate.

We define a prefecture-level YCI in a manner similar to the Hirschman-Herfindahl index. Let $G$ be the set of all 21 (designated) yakuza syndicates, and let $s_{p g}$ be the "share" of yakuza syndicate $g \in G$ in prefecture $p$, which is defined below. It would be desirable to use data on the number of members of each yakuza syndicate in each prefecture to calculate the share, but such data do not exist. We thus need to estimate these figures. For now, let us assume that the members of each yakuza syndicate $g$ are distributed over the prefectures where the syndicate operates proportionally to the population of each of the prefectures. (To examine the robustness of our estimation, we will modify this assumption in Appendix A.) Since we know the total number of members of each yakuza syndicate, we can calculate the share $s_{p g}$ under this assumption. To define the share $s_{p g}$, we estimate the number of members of yakuza syndicate $g$ in prefecture $p$. Let $P_{g}$ be the set of prefectures where yakuza syndicate $g$ operates, and let $q_{p}$ be the population in prefecture $p$. For a yakuza syndicate $g$, the population ratio of prefecture $p \in P_{g}$ to all the prefectures in which yakuza syndicate $g$ operates equals $q_{p} / \sum_{p^{\prime} \in P_{g}} q_{p^{\prime}}$. Hence, the estimated number of members of yakuza syndicate $g$ in prefecture $p$, denoted $N_{g p}$, is the total number of members of yakuza syndicate $g$ times the population ratio $q_{p} / \sum_{p^{\prime} \in P_{g}} q_{p^{\prime}}$. We define the share of yakuza syndicate $g$ in prefecture $p$ by $s_{p g}=N_{g p} / \sum_{g^{\prime} \in G_{p}} N_{g^{\prime} p}$ if $g \in G_{p}$ and $s_{p g}=0$ if $g \notin G_{p}$, where $G_{p}$ is the set of yakuza syndicates that operate in prefecture $p$. By definition, we have $0 \leq s_{p g} \leq 1$ and $\sum_{g} s_{p g}=1$ for each $p, g$ (since there is at least one yakuza syndicate in every prefecture). Given these shares, we define the YCI of prefecture $p$, denoted $Y C I_{p}$, by $Y C I_{p}=1-\sum_{g \in G} s_{p g}^{2}$. Note that $Y C I_{p}=0$ if there is only one (monopolistic) syndicate in prefecture $p$ and $Y C I_{p}$ increases in the number of yakuza syndicates in prefecture $p$.

We treat YCI as time-independent and measure it using the data prior to the enactment of the 
YEOs (the 2009 data), because if the YEOs affect YCI, then YCI is considered a post-treatment covariate, inducing post-treatment bias. ${ }^{8}$

Control Variables. We control for a host of demographic and socioeconomic variables: the $\log$ of overall population, the proportion of males, the proportion of individuals aged 15-24, the proportion of individuals aged 25-34, the proportion of individuals aged over 65, the proportion of foreign people, the population density, the GDP, and the number of welfare recipients per 1,000 inhabitants. The data on demographic and socioeconomic variables are publicly available on e-Stat (a portal site for Japanese Government Statistics). Since the data are collected yearly, we impute monthly values using linear interpolation. See Appendix F for the summary statistics of these control variables.

\subsection{Identification Strategy}

Difference-in-Differences Strategy. We use a difference-in-differences (DiD) identification strategy by exploiting monthly variations in the enactment dates of the YEOs. Moreover, we allow for treatment effect heterogeneity by a cross-sectional variation of YCI. Taken together, our main regression model is:

$$
y_{p t}=\beta_{1} Y E O_{p t}+\beta_{2} Y E O_{p t} \times Y C I_{p}+\eta X_{p t}+\mu_{p}+\xi_{t}+\sum_{r \in R} \delta_{p r} \rho_{r} t+\varepsilon_{p t} .
$$

Here, $y_{p t}$ is the log of the revenue of organized fraud in prefecture $p$ at time $t . Y E O_{p t}$ is a treatment dummy that equals 1 if the YEOs are in effect in prefecture $p$ at time $t$ and 0 otherwise. ${ }^{9} Y C I_{p}$ is the YCI of prefecture $p$. YEO $O_{p t} \times Y C I_{p}$ allows for heterogeneity of the effects of the YEOs with respect to the YCIs. $X_{p t}$ are controls. $\mu_{p}$ is a prefecture fixed effect, which captures time-invariant unobservables, such as the yakuza culture and non-yakuza individuals' attitudes toward the yazuka. $\xi_{t}$ is a month-year fixed effect, which controls for common time-specific effects on all prefectures. For instance, technological developments such as smartphones may make it easier to commit crimes. $\sum_{r} \delta_{p r} \rho_{r} t$ captures region-specific time trends, which capture regional unobservables that vary over time. It is important to capture such regional unobservables since the YCIs are regionally clustered, as illustrated in Figure 4. In this study, Japan is divided into seven regions: Hokkaido-Tohoku, Kanto, Chubu, Kansai, Chugoku, Shikoku, and Kyushu-Okinawa. Let $R$ be the set of these regions. $\delta_{p r}$ is a treatment dummy that equals 1 if prefecture $p$ is in region $r$ and 0 otherwise. $\rho_{r}$ is a regionspecific time trend. $\varepsilon_{p t}$ is an idiosyncratic error. We utilize weighted least squares, using the prefectural populations as weights. Standard errors are clustered at the prefecture level to adjust for serial correlation within the same prefecture (Bertrand et al., 2004).

\footnotetext{
${ }^{8}$ In Appendix A, we conduct several robustness checks using alternative indices. First, we use alternative definitions of yakuza shares $s_{p g}$ and resulting YCIs. Second, we use alternative definitions of the concentration indices of the yakuza syndicates. Our empirical results are robust to all these specifications.

${ }^{9}$ We use monthly panel data. By time $t$, we mean the $t$-th month in our dataset. Using a dataset beginning in January 2011, for example, we refer to January 2011 as $t=1$, to January 2012 as $t=13$, to January 2013 as $t=25$, and so on.
} 
We note that local governments' decisions to enact the YEOs may not be completely random. For instance, the local governments may take into consideration local yakuza activity. Fukuoka is the first prefecture that enacted the YEOs because of elevated yakuza conflicts. Nevertheless, there was a nationwide movement to strengthen regulations on the yakuza, so the local governments should have had little discretion. Furthermore, our placebo test in the event-study design suggests that the treatment effects are not driven by the pre-existing conditions of the revenue from organized fraud.

Event-Study Analysis. We study the dynamics of the YEOs' effects on the revenue of organized fraud by examining the six months before the enactment of the YEOs and the twelves months following the YEOs' enactment in an event-study framework. The event-study framework has two purposes. First, we indirectly test the parallel trend assumption by including leads for treatment indicators. The parallel trend assumption is the identifying assumption for the DiD design. It states that in the absence of treatment, treated and control groups follow similar trends concerning the outcome of interest (e.g., Angrist and Pischke, 2008). This assumption could be violated, however, if timing of the the YEOs' enactment reflected public concern about the recent surge in the organized fraud. To indirectly assess the parallel trends assumption, we include lead treatment indicators, which assess the pre-existing trends in the organized fraud between prefectures that enacted the YEOs and those that have not yet enacted the YEOs.

Second, we include lagged treatment indicators to explore whether an increase in the revenue from the organized fraud is persistent after the YEOs' enactment. If the YEOs' effects are persistent, the coefficients for the months following the YEOs' enactment should be large in magnitude and statistically significant. Here is the regression model for the event-study design:

$$
y_{p t}=\sum_{\tau=-12}^{6} \alpha_{\tau} Y E O_{p, t+\tau}^{\prime}+\beta Y E O_{p t} \times Y C I_{p}+\eta X_{p t}+\mu_{p}+\xi_{t}+\sum_{r \in R} \delta_{p r} \rho_{r} t+\varepsilon_{p t} .
$$

Following Autor (2003), we let the treatment indicators for 1- to 6-month leads and 1- to 12-month lags of the YEOs' enactment take the value of 1 only for relevant months and the value of 0 otherwise. Coefficient $\alpha_{\tau}$ measures the effect of the $(-\tau)$-month lag effect of the YEOs if $\tau<0$ and the $\tau$-month lead effect if $\tau>0$. In this notation, $\alpha_{0}, \beta$ correspond to $\beta_{1}, \beta_{2}$ in regression (1) respectively. We also let $Y E O_{p, t-12}^{\prime}=1$ for all $t$ twelve or more months later than the YEO enactment in prefecture $p$, and we let and $Y E O_{p, t+6}^{\prime}=1$ for all $t$ six or more months earlier than the YEO enactment in prefecture $p$.

\section{Main Results}

\subsection{YEOs' Effects on Organized Fraud}

Table 2 reports the YEOs' effects on the log of the revenue generated by organized fraud. Panel A reports our baseline estimates, which do not allow for heterogeneous effects of the YEOs by 
the YCIs (i.e., $\beta_{2}=0$ ), while Panel $\mathrm{B}$ reports estimates that allow for such heterogeneity. In each panel, we have considered the following four specifications: (1) no region-specific trends; (2) region-specific linear trends; (3) region-specific quadratic trends; and (4) both linear and quadratic trends.

In Panel A, the YEOs' effects are significantly positive in all the specifications, which suggests that the YEOs increase the revenue from organized fraud. The estimates suggest that the YEOs increase the revenue of organized fraud by approximately 30-37\%. Given that the financial damage by organized fraud has, on average, grown by $85 \%$ from 2011 to 2013 , our estimates indicate that the YEOs account for 35-43\% of the recent increase. In Panel B, consistent with the estimates in Panel A, the YEOs' effects are significantly positive, indicating that the YEOs increase the revenue from organized fraud by approximately 100-130\% in prefectures with a zero YCI. The interaction term $Y E O_{p t} \times Y C I_{p}$ is significantly negative. That is, the strength of the YEOs' effects decreases as the YCI increases.

Based on the specification (4), the downward slope in Figure 5 illustrates the heterogeneity of the YEOs' effects by the YCI in two ways. First, the solid line, together with the gray band, indicates the marginal effect of the YEOs with the $95 \%$ confidence intervals when we treat the YCI as a continuous variable. Second, the three dots, with the black dashed lines, indicate the binned estimates suggested by Hainmueller et al. (2019); the marginal effect of the YEOs evaluated at the low YCI, the medium YCI, and the high YCI. These results are consistent in the sense that the effect of the YEOs is greater in prefectures with lower YCI. Taken together, we find that the YEOs increase the revenue from organized fraud by roughly $37-42 \%$ when evaluated at the mean of YCI.

\subsection{Event-Study Analysis}

Figure 6 reports the estimates of the event-study analyses with $95 \%$ confidence intervals. The left panel illustrates the YEOs effect on the revenue from organized fraud conditional on the YCIs taking the value of zero. Analogously, the right panel illustrates the YEOs effect on the same outcome conditional on the YCIs taking the mean value. As illustrated in Figure 5, we note that the YEOs effects decrease in the YCI and thus are not statistically significant at high YCI. Therefore, we only provide graphical evidence up to the mean value of the YCI.

This event-study analysis has two purposes. First, it examines the trend of the outcome in months leading to the enactment of the YEOs by including the lead treatment indicators. If the parallel trends assumption is satisfied, the coefficients of the lead treatment indicators should be close to zero. Since the future treatment status (i.e., the lead treatment indicators) should have no significant effects if the treatments had causal effects, the null effects of the lead treatment indicators serve as a placebo test. Second, the analysis examines the trend of the outcome in months following the enactment of the YEOs by including the lag treatment indicators. This explores whether the YEOs effects persist for the 12 months following the YEOs enactment.

It is illustrated in Figure 6 that the coefficients $\alpha_{\tau}$ for the lead treatment indicators are close to zero, but as soon as the YEOs are enacted, the coefficients $\alpha_{\tau}$ for the lagged treatment indicators 
Table 2: YEOs' Effects on Revenue from Organized Fraud

\begin{tabular}{|c|c|c|c|c|}
\hline \multicolumn{5}{|c|}{ Dependent Variable: ln Revenues of Organized Fraud } \\
\hline YEO & $\begin{array}{c}0.263^{* *} \\
(0.129)\end{array}$ & $\begin{array}{c}0.292^{* *} \\
(0.143)\end{array}$ & $\begin{array}{c}0.288^{* *} \\
(0.142)\end{array}$ & $\begin{array}{c}0.316^{* *} \\
(0.147)\end{array}$ \\
\hline R-squared & 0.259 & 0.271 & 0.271 & 0.274 \\
\hline Panel B: & (1) & $(2)$ & (3) & (4) \\
\hline YEO & $\begin{array}{c}0.729^{* *} \\
(0.316)\end{array}$ & $\begin{array}{c}0.780 * * \\
(0.308)\end{array}$ & $\begin{array}{c}0.773^{* *} \\
(0.308)\end{array}$ & $\begin{array}{c}0.820^{* *} \\
(0.314)\end{array}$ \\
\hline $\mathrm{YEO} \times \mathrm{YCI}$ & $\begin{array}{c}-0.898^{*} \\
(0.490)\end{array}$ & $\begin{array}{c}-0.970^{* *} \\
(0.460)\end{array}$ & $\begin{array}{c}-0.955^{* *} \\
(0.460)\end{array}$ & $\begin{array}{c}-1.036^{* *} \\
(0.477)\end{array}$ \\
\hline Overall Effects (Evaluated at Mean) & $\begin{array}{c}0.376^{* *} \\
(0.149)\end{array}$ & $\begin{array}{c}0.400^{* *} \\
(0.156)\end{array}$ & $\begin{array}{c}0.398^{* *} \\
(0.155)\end{array}$ & $\begin{array}{c}0.413^{* *} \\
(0.155)\end{array}$ \\
\hline Adjusted R-squared & 0.262 & 0.273 & 0.272 & 0.275 \\
\hline Observations & 1,613 & 1,613 & 1,613 & 1,613 \\
\hline Control Variables & $\checkmark$ & $\checkmark$ & $\checkmark$ & $\checkmark$ \\
\hline Prefecture Fixed Effects & $\checkmark$ & $\checkmark$ & $\checkmark$ & $\checkmark$ \\
\hline Month $\times$ Year Fixed Effects & $\checkmark$ & $\checkmark$ & $\checkmark$ & $\checkmark$ \\
\hline Region-specific Trends & No & Linear & Quadratic & Both \\
\hline
\end{tabular}

Notes: The revenue of organized fraud is its financial damage per case. Control Variables: the log of overall population, the proportion of males, the proportion of individuals aged 15-24, the proportion of individuals aged 25-34, the proportion of individuals aged over 65, the proportion of foreign people, the population density, the GDP, and the welfare recipients per 1,000 inhabitants. Standard errors in parentheses are clustered at the prefecture level.

Significance at the $1 \%, 5 \%$, and $10 \%$ levels indicated by $* * *, * *$, and $*$, respectively.

increase sharply and this effect is stable for the subsequent 12 months. Therefore, the pretreatment trends by themselves appear to be unable to explain the change of the revenue from organized fraud. It supports the parallel trend assumption in our DiD analyses.

The result from the event-study analysis reveals that the revenue from the organized fraud jumps up within one month after the YEOs enactment. In addition, although the prefectural authorities made an announcement of the YEOs enactment in advance, the revenue from the organized fraud was stable and close to zero until the enactment. That is, no announcement effect is observed. This can be rationalized as follows. First, we note that yakuza members should have enjoyed traditional income sources before the YEOs enactment. If these traditional income sources are more profitable and stable than the organized fraud, yakuza members would have stuck to the traditional ones if it were not for the YEOs. As soon as the prefectural authorities enacted the YEOs, the yakuza members might have shifted their illegal activities from their traditional ones to the organized fraud. Second, we note that the organized fraud requires a variety of sophisticated criminal skills (National 
Figure 5: Marginal Effects of YEOs on Revenue from Organized Fraud with 95\% CIs

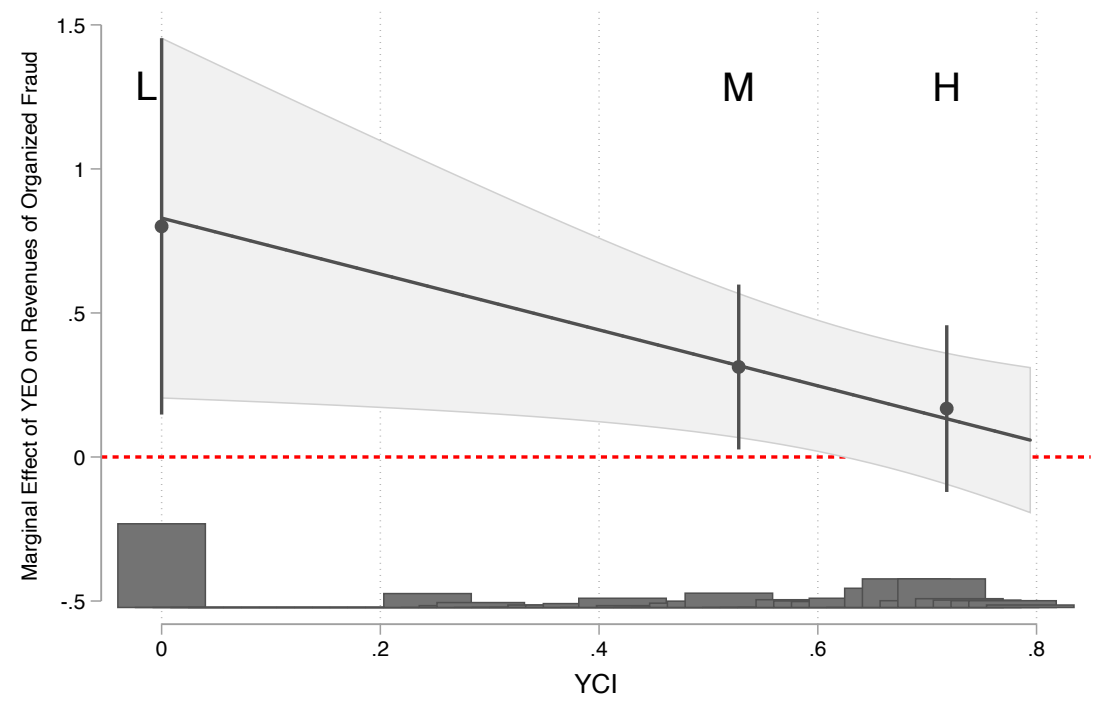

Notes: The revenue of organized fraud is its financial damage by organized fraud per case. Control Variables: the $\log$ of overall population, the proportion of males, the proportion of individuals aged 15-24, the proportion of individuals aged 25-34, the proportion of individuals aged over 65, the proportion of foreign people, the population density, the GDP, and the number of welfare recipients per 1,000 inhabitants.

Police Agency, 2015). Thus, yakuza members, who anticipated their economic difficulties in the near future due to the YEOs, should have prepared for the difficulties, for example, by looking for crime partners to switch over to the organized fraud. This hypothesis has the following supports. Yakuza members are reported to be involved in non-yakuza organized fraudsters (National Police Agency, 2015, 2018). Moreover, as indicated in the interview (NHK, 2018), former yakuza members are often affiliated with other non-yakuza criminals for organized fraud. Taken together, the interval between the announcement and enactment of the YEOs serves as a period to prepare for a new type of crime - the organized fraud.

\subsection{Permutation Test}

Since pre-treatment periods for data on communication frauds are short, we run an additional placebo test to ensure that the estimated effects of the YEOs are causal (e.g., Abadie et al., 2010, 2015). In this exercise, we randomly vary the enactment dates of the YEOs across prefectures, and we call the randomly assigned enactment dates placebo treatments. The intuition behind this exercise is that if the estimated effects of the YEOs are causal, then the estimates that are derived from the placebo treatments should not have significant effects. For this test, we redraw placebo treatments randomly and reestimate placebo treatment effects. We iterate this process 10,000 times. Figure 7 shows the resulting distribution of the estimated placebo coefficients. In the figure, the dashed line indicates the upper $95 \%$ of the distribution of the placebo coefficients; 
Figure 6: Event-Study Analysis of YEOs Effects on Revenue from Organized Fraud

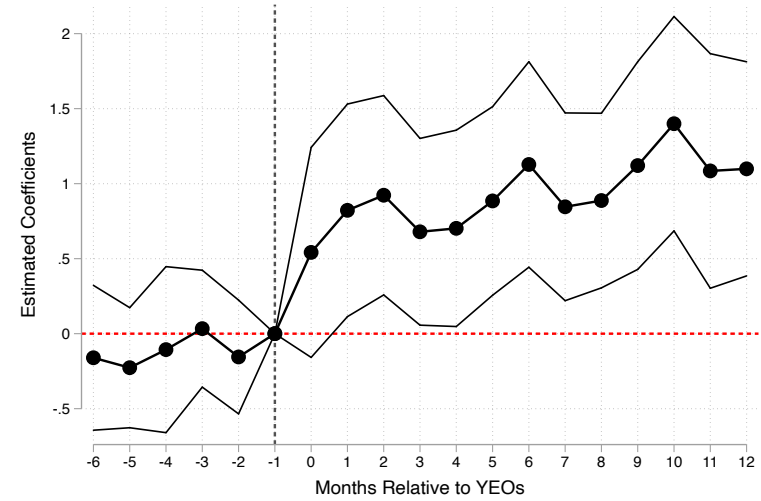

YEOs Effects Evaluated at YCI = Zero

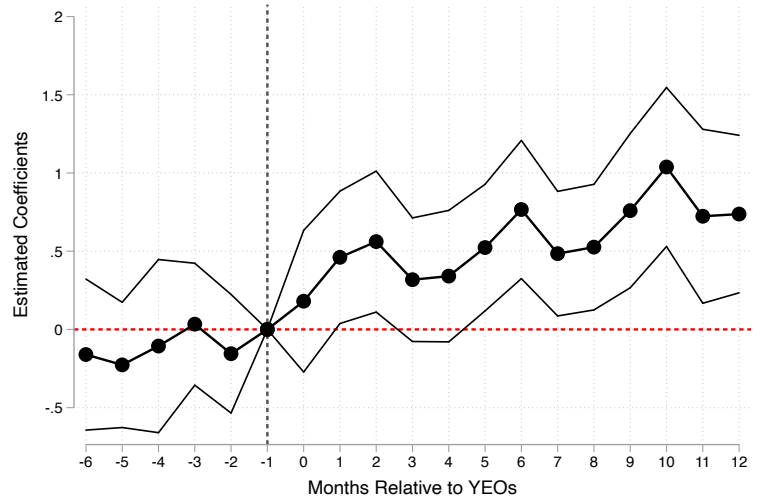

YEOs Effects Evaluated at YCI = Mean

Notes: The revenue of the organized fraud is the financial damage of organized fraud per case. Control Variables: the log of overall population, the proportion of males, the proportion of individuals aged 15-24, the proportion of individuals aged 25-34, the proportion of individuals aged over 65, the proportion of foreign people, the population density, the unemployment rate, and the GDP.

the red line represents the estimated effect from Column 4 in Panel A in Table 2. If the YEOs' effects are causal, then the estimated coefficients indicated by the red line, should be at the right (or left) tail of the distribution of placebo coefficients, indicated by the dashed line. Indeed, this is exactly what Figure 7 shows. Hence, we conclude that it is less likely that the estimated effects of the crack epidemic are driven by randomness or idiosyncrasy.

\section{Channels}

We turn our attention to channels through which the YEOs increase the revenue from organized fraud. Specifically, we examine two possible channels. First, former yakuza members might have committed the organized fraud since there are scarce legitimate economic opportunities for them. Second, current yakuza members might have engaged in the organized fraud because the YEOs financially damage their syndicates.

\subsection{Fraud by Former Yakuza Members}

The number of former yakuza members is unknown, but the number of the current ones is known. A decrease in the number of the current ones increases that of the former ones. This simple fact suggests that the change in the current ones can be used as a proxy for the change in the former ones. To test whether the former ones engage in the organized fraud, we examine how the cumulative change in the yakuza rates since the enactment of the YEOs is associated with the revenue from 
Figure 7: Permutation Test: Revenue from Organized Fraud

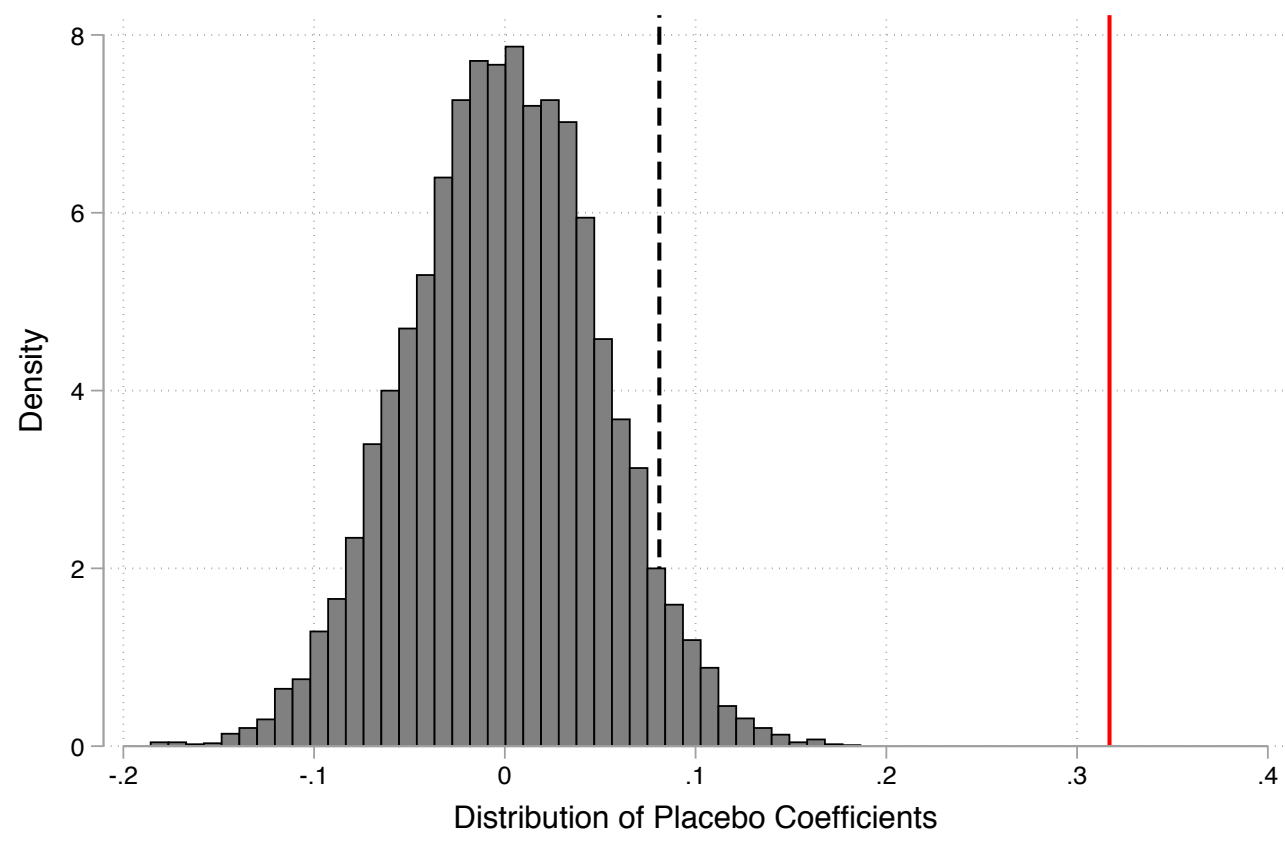

Notes: Red line: baseline estimates taken from Column (4) in Panel A Table 2. Dashed line: estimates derived from placebo treatments. Permutation tests: 10,000 times.

the organized fraud. Our regression model is:

$$
y_{p t}=\gamma_{1} \Delta_{p t}^{d}+\gamma_{2} \Delta_{p t}^{0} \times Y C I_{p}+\eta X_{p t}+\mu_{p}+\xi_{t}+\sum_{r \in R} \delta_{p r} \rho_{r} t+\varepsilon_{p t}
$$

Here, $y_{p t}$ is the log of the revenue from organized fraud. Let $\ln Y a k u z a_{p}$ denote the yakuza rate in prefecture $p$ at the time of the YEOs enactment, and let $\ln Y a k u z a_{p t}$ denote the yakuza rate in prefecture $p$ at time $t$. For time $t$ after the YEOs enactment in prefecture $p$, let $\Delta_{p t}^{0}=\ln Y a k u z a_{p t}-$ $\ln Y a k u z a_{p}$ be the cumulative change in the yakuza rates since the time of the YEOs enactment. Let $\Delta_{p t}^{1}=\Delta_{p t}^{0}-\Delta_{p t-1}^{0}, \Delta_{p t}^{2}=\Delta_{p t}^{0}-\Delta_{p t-2}^{0}$, and so on, which capture the dynamic effect. Furthermore, we allow the change in the log of yakuza members to depend on the YCI by including the interaction term $\Delta_{p t}^{0} \times Y C I_{p}$. The previous results suggest that the YEOs' effect is greater in prefectures with lower concentration of yakuza syndicates. If former yakuza members engage in the organized fraud more in such prefectures, then we should find a positive coefficient on the interaction term.

In Table 3, we report our estimates. Columns (1) to (6) correspond to the regression model (3) with $d=0,1, \ldots, 5$ respectively. Since the number of yakuza members is on the decline, the differences of the yakuza rates are negative. Thus, the negative coefficients imply that a decrease in the number of yakuza members is positively correlated with the revenue from organized fraud. It is suggested that as the number of yakuza members decreases - namely, as the number of former yakuza members increases - the revenue from organized fraud increases. Furthermore, the 
Table 3: Changes in Yakuza Rates and Revenue from Organized Fraud

\begin{tabular}{|c|c|c|c|c|c|c|}
\hline Dependent Variable: $\ln$ Re & $\begin{array}{l}\text { nues of } \\
(1)\end{array}$ & $\begin{array}{l}\text { Prganize } \\
\quad(2)\end{array}$ & $\begin{array}{l}\text { Fraud } \\
\qquad(3)\end{array}$ & (4) & $(5)$ & (6) \\
\hline$\Delta$ ln Yakuza Rates & $\begin{array}{c}-0.480 \\
(0.722)\end{array}$ & $\begin{array}{c}-1.006^{*} \\
(0.584)\end{array}$ & $\begin{array}{l}-1.006 \\
(0.620)\end{array}$ & $\begin{array}{c}-1.165^{*} \\
(0.589)\end{array}$ & $\begin{array}{c}-1.176^{* *} \\
(0.574)\end{array}$ & $\begin{array}{c}-1.132^{* *} \\
(0.532)\end{array}$ \\
\hline$\Delta$ ln Yakuza Rates $\times$ YCI & $\begin{array}{c}0.880 \\
(1.074)\end{array}$ & $\begin{array}{l}1.660^{*} \\
(0.910)\end{array}$ & $\begin{array}{l}1.652^{*} \\
(0.960)\end{array}$ & $\begin{array}{c}1.898^{* *} \\
(0.919)\end{array}$ & $\begin{array}{c}1.910^{* *} \\
(0.895)\end{array}$ & $\begin{array}{c}1.840^{* *} \\
(0.830)\end{array}$ \\
\hline Observations & 1,177 & 1,176 & 1,174 & 1,172 & 1,170 & 1,168 \\
\hline R-squared & 0.271 & 0.273 & 0.273 & 0.274 & 0.273 & 0.274 \\
\hline Time Difference $d$ & 0 & 1 & 2 & 3 & 4 & 5 \\
\hline Prefecture Fixed Effects & $\checkmark$ & $\checkmark$ & $\checkmark$ & $\checkmark$ & $\checkmark$ & $\checkmark$ \\
\hline Time Fixed Effects & $\checkmark$ & $\checkmark$ & $\checkmark$ & $\checkmark$ & $\checkmark$ & $\checkmark$ \\
\hline Control Variables & $\checkmark$ & $\checkmark$ & $\checkmark$ & $\checkmark$ & $\checkmark$ & $\checkmark$ \\
\hline Region Specific Trends & $\checkmark$ & $\checkmark$ & $\checkmark$ & $\checkmark$ & $\checkmark$ & $\checkmark$ \\
\hline
\end{tabular}

Notes: The revenue of the organized frauds is its financial damage per case. The yakuza rates are the number of yakuza members per 100,000 inhabitants. Control Variables: the log of overall population, the proportion of males, the proportion of individuals aged 15-24, the proportion of individuals aged 2534 , the proportion of individuals aged over 65, the proportion of foreign people, the population density, the GDP, and the welfare recipients per 1,000 inhabitants.

Standard errors in parentheses are clustered at the prefecture level. Significance at the 1\%, 5\%, and $10 \%$ levels indicated by $* * *, * *$, and $*$, respectively.

coefficients of the interaction term are positive and statistically significant. Thus, the effect of the change in yakuza members on the revenue from organized fraud is smaller in prefectures with lower YCI. It is, therefore, suggested that an increase in former yakuza members is associated with the revenue from organized fraud, and its association is greater in prefectures with lower concentration of yakuza syndicates.

\subsection{Fraud by Current Yakuza Members}

Next, we test whether current yakuza members engage in organized fraud. From the data used in the previous analyses, we cannot determine which organized fraud is committed by (current) yakuza members. We use another set of data on the arrests of yakuza members in Tokyo. In particular, we use the number of arrests of (current) yakuza members for fraud as a proxy measure of the yakuza's involvement in organized fraud.

It is important to note that arrest data may reflect the unobservable level of law enforcement, and thus using this proxy may cause an endogeneity problem. If the YEOs increased law enforcement by the police, it would be difficult to interpret the YEOs' effects. There are two possible interpretations of an increase in the arrests of yakuza members. One is that the offenses by yakuza members increase, as we hypothesize. The other is that the police arrest more members although the yakuza themselves do not change their illegal behavior. We argue, however, that the latter is less 
convincing for the following reason: if the latter held, not only would the number of yakuza arrests for fraud and other crimes increase. In addition to fraud, we examine yakuza arrests for crimes that yakuza members are often involved in to test this possibility indirectly. In particular, we examine the effects on the number of arrests for extortion, the sale and possession of methamphetamine, overall property, and violent crime.

We use ward-level data on the arrests of current yakuza members. The dataset is published annually by the Tokyo Metropolitan Police Department, which covers the period from 2004 to 2013. We restrict our sample to the period from 2009 to 2013. Our research design is similar to interrupted time-series analysis, which exploits the introduction of the YEO in Tokyo in 2011. A caveat of this approach is that since there is no data of cross-sectional variation in the enactment dates, the effects of the YEOs in Tokyo are indistinguishable from other macro shocks that may affect the number of yakuza arrests. For this reason, we need to be cautious about interpreting empirical results. Since the arrest data are count data, we use the Poisson pseudo-maximum likelihood (PPML) estimation. ${ }^{10}$ We regress the conditional expectation as follows:

$$
\ln \mathbb{E}\left[y_{w y} \mid Y E O_{y}, X_{w y}\right]=\beta Y E O_{y}+\eta X_{w y}+\mu_{w}+\xi_{y}+\varepsilon_{w y}
$$

$y_{w y}$ is the number of arrests of (current) yakuza members for fraud or other types of crime in ward $w$ in year $y . Y E O_{y}$ is a treatment dummy that equals 1 if the YEOs are in effect in Tokyo and 0 otherwise. $X_{w y}$ is control variables, including the proportion of males, the average age, the proportion of people older than 65 , the proportion of foreign residents, the number of welfare recipients per 1,000 inhabitants, and the taxable income. We obtain these data from the Tokyo Statistical Yearbook (Table A6). Then, $\mathbb{E}\left[y_{w y} \mid Y E O_{y}, X_{w y}\right]$ is the expected value of $y_{w y}$ conditional on both $Y E O_{y}$ and $X_{w y} . \quad \mu_{w}$ is a ward-level fixed effect. $\xi_{y}$ is a year fixed effect. $\varepsilon_{w y}$ is an idiosyncratic error. All regressors are weighted by the ward population. Standard errors are clustered at the ward level.

Figure 8 reports our estimation results. The coefficient of the YEOs in Tokyo is significantly positive for the number of arrests for fraud. It suggests a $28 \%$ increase in the arrest for fraud. In contrast, the coefficients are not significant for the number of arrests for extortion, methamphetamine, overall property crime, and violent crime. Except for overall violent crime, the estimates rather suggest negative trends. These are reasonable results, given that the YEOs decrease the number of yakuza members, so that potential yakuza members who may be arrested are necessarily on the decline. In contrast, despite the fact that the number of yakuza members is on decline, the YEO's effect in Tokyo is positive and statistically significant for yakuza arrests for fraud. Therefore, the estimate is considered to be downwardly biased and thus a lower bound. The analysis provides suggestive evidence that the YEOs do not increase the level of law enforcement, but rather the YEOs increase fraud committed by current yakuza members.

\footnotetext{
${ }^{10}$ The Poisson model has several advantages (Wooldridge, 2010). It is consistent under mild distributional assumptions. It also does not suffer from the incidental parameters problem, and thus we can control for ward-level fixed effects.
} 
Figure 8: Effects of the YEOs on Arrests of Yakuza Members in Tokyo with 95\% CI

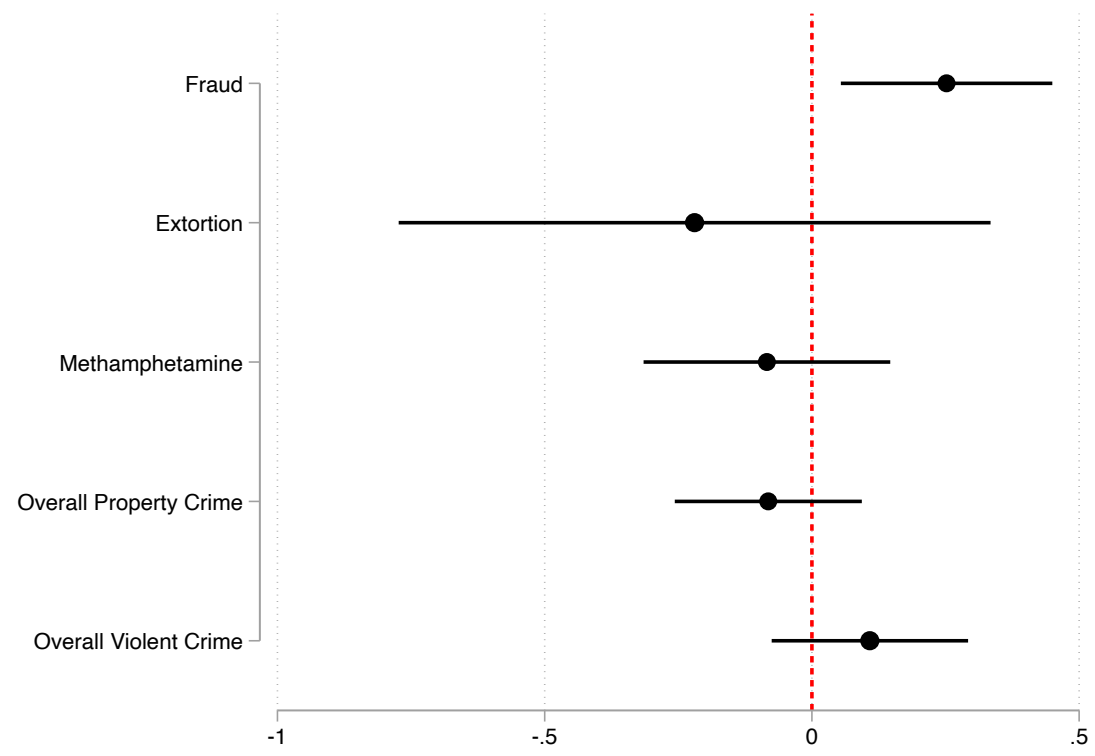

Control Variables: the proportion of males, the average age, the proportion of individuals aged over 65 , the proportion of foreign residents, the number of welfare recipients per 1,000 inhabitants, and the taxable income. Data Sources: the yakuza arrest data from the Tokyo Metropolitan Police Department; the control variable data from e-Stat.

\subsection{Other Outcomes}

We examine other outcomes that may be affected by the YEOs, to better understand the YEOs' social impact on welfare. First, we examine the effects both on overall violent crime and on overall property crime. Violent crime includes murder, robbery, arson, rape, abduction, human trafficking and sexual assault, while property crime includes burglary, motor vehicle theft, snatching, and pickpocketing; both measures are available from the NPA. The outcomes here are defined as the $\log$ of the number of each type of crime per 100,000 residents. We use monthly-level data from 2010 to 2013. Columns (1) and (2) show the results, and neither the coefficient of the YEOs and the coefficient of the interaction term of the YEOs and YCI is statistically significant and small in magnitude. Second, we examine the impact on legitimate business by examining the number of business bankruptcies and the amounts of business debt. The outcomes here are defined as the log of the number of business bankruptcies per 100,000 residents and the log of the debt amount; both measures are available from the business mutual aid association research and investigation reports. We use monthly-level data from 2010 to 2013. Column (3) shows that the neither the coefficient of the YEOs nor the coefficient of the interaction term of the YEOs and YCI is statistically significant. Column (4) finds that while the coefficient of the YEOs is positive but marginally significant, the coefficient of the interaction term of the YEO and YCI is not significant. These results, therefore, suggest that the YEOs do not necessarily improve the economic welfare, but rather there could be 
a trend, if any, that they may also exacerbate it.

Table 4: YEOs' Effects on Other Outcomes

\begin{tabular}{lcccc}
\hline \hline & $(1)$ & $(2)$ & $(3)$ & $(4)$ \\
& Violent Crime & Property Crime & Bankruptcy & Debt \\
\hline \multirow{2}{*}{ YEO } & 0.014 & 0.002 & -0.033 & $0.216^{*}$ \\
& $(0.029)$ & $(0.035)$ & $(0.052)$ & $(0.124)$ \\
YEO $\times$ YCI & -0.002 & 0.015 & -0.010 & -0.206 \\
& $(0.030)$ & $(0.049)$ & $(0.066)$ & $(0.175)$ \\
& & & & \\
\hline Observations & 2,256 & 2,256 & 2,256 & 2,256 \\
R-squared & 0.735 & 0.899 & 0.750 & 0.750 \\
Control Variables & $\checkmark$ & $\checkmark$ & $\checkmark$ & $\checkmark$ \\
Prefecture Fixed Effects & $\checkmark$ & $\checkmark$ & $\checkmark$ & $\checkmark$ \\
Month $\times$ Year Fixed Effects & $\checkmark$ & $\checkmark$ & $\checkmark$ & $\checkmark$ \\
Region-specific Trends & Both & Both & Both & Both \\
\hline
\end{tabular}

Notes: Violent crime: an aggregate variable including murder, robbery, arson, rape, abduction, human trafficking and sexual assault. Property crime: an aggregate variable including burglary, motor vehicle theft, snatching, and pickpocketing. Bankruptcy: the number of firm bankruptcies per 100,000 residents. Debt: the debt amount. Control Variables: the log of overall population, the proportion of males, the proportion of individuals aged 15-24, the proportion of individuals aged 25-34, the proportion of individuals aged over 65, the proportion of foreign people, the population density, the unemployment rate, and the GDP.

Standard errors in parentheses are clustered at the prefecture level. Significance at the 1\%, 5\%, and $10 \%$ levels indicated by $* * *, * *$, and $*$, respectively.

\section{Concluding Remarks}

We have examined the effects of the recent crackdown on the yakuza, called the Yakuza Exclusion Ordinances (YEOs). The YEOs apply economic sanctions on the yakuza indirectly by prohibiting non-yakuza from providing benefit to the yakuza, instead of intervening in the yakuza directly. This novel approach is suggested to be effective at reducing the number of yakuza members, but we point out that it does not necessarily mean that the YEOs have improved the public security. In the present study, we shed light on collateral consequences associated with the YEOs. We argue that the YEOs increase a new type of crime because the YEOs cripple existing economic opportunities for the yakuza. In particular, we have focused our attention to organized fraud. This kind of crime has surged in Japan, accounting for nearly half of the total financial damage related to property crimes in Japan.

Our main results are two-fold: (i) the YEOs increase the revenue generated by organized fraud; and (ii) the strength of the YEOs' effects decreases as the YCI increases, where the YCI is regional concentration indices of yakuza syndicates. Given that the revenue from this fraud increased by $80 \%$ during the period of our study, our estimates suggest the YEOs account for nearly $40 \%$ of the recent surge in organized fraud. Our results survive a variety of robustness checks, including the 
parallel-trend assumption and permutation test.

We then examine two potential channels, indicating that both former and current yakuza members engage in organized fraud in the presence of the YEOs. First, using a change in the number of yakuza members as a proxy for former yakuza members, we show that a cumulative change in yakuza members since the enactment of the YEOs is negatively correlated with the revenue from organized fraud, its association is greater in prefectures with lower concentration of yakuza syndicates. This result is consistent with the following perspective. Once the YEOs have been enacted, the number of former yakuza members increases, especially in prefectures with lower YCI. Since former yakuza members have economic difficulties and thus may be driven to organized fraud in those prefectures. Second, using arrest data of current yakuza members in Tokyo, we provide evidence suggesting that the YEOs in Tokyo increase the arrest of the yakuza for fraud, but not for other types of crime. This result rules out the possibility that the observed increase in the arrest is due to the increase in the level of policing enforcement. This result also can be rationalized along the following interpretation. The YEOs make it difficult for (current) yakuza members to exploit traditional income sources from non-yakuza individuals. The yakuza thus need to substitute the traditional income sources with new ones, in particular organized fraud.

We draw two important policy implications from our empirical findings. First, to prevent former yakuza members - or more broadly, former gang members - from committing crimes, it is important to assist them to rehabilitate into (lawful) society. In 2016, several prefectural police departments, in cooperation with legitimate firms, introduced a program to subsidize the firms that hire former yakuza members. This is expected to provide better opportunities for rehabilitation. It is, therefore, important to evaluate the effectiveness of this type of program to understand whether it can reduce not only yakuza members but also lucrative crime, such as organized fraud. Second, the heterogeneity of the YEOs effects by the YCI suggests that the YEOs effectiveness may be affected by strategic relationship among yakuza syndicates. When criminal organizations compete with one another, these relationships may serve as a powerful tool to leverage regulation effectiveness. Intensive attack on a few criminal organizations may be more effective than attacking extensive (but weaker) attack on many criminal organizations. This is because as one criminal organization becomes weaker, its rivals become less willing to maintain the power of the rivals' own. Combining the two implications, we say that rehabilitation assistance to former yakuza members is effective in regions with less yakuza competition.

\section{References}

Abadie, Alberto, Alexis Diamond, and Jens Hainmueller. 2010. "Synthetic control methods for comparative case studies: Estimating the effect of California's tobacco control program." Journal of the American statistical Association 105:493-505.

Abadie, Alberto, Alexis Diamond, and Jens Hainmueller. 2015. "Comparative politics and the synthetic control method." American Journal of Political Science 59:495-510.

Angrist, Joshua D and Jörn-Steffen Pischke. 2008. Mostly harmless econometrics: An empiricist's companion. Princeton university press. 
Autor, David H. 2003. "Outsourcing at will: The contribution of unjust dismissal doctrine to the growth of employment outsourcing." Journal of Labor Economics 21:1-42.

Becker, Gary S. 1968. "Crime and punishment: An economic approach." Journal of Political Economy 76:169-217.

Bertrand, Marianne, Esther Duflo, and Sendhil Mullainathan. 2004. "How much should we trust differencesin-differences estimates?" Quarterly Journal of Economics 119:249-275.

Braga, Anthony A, David M Hureau, and Andrew V Papachristos. 2014. "Deterring gang-involved gun violence: Measuring the impact of Boston's Operation Ceasefire on street gang behavior." Journal of Quantitative Criminology 30:113-139.

Braga, Anthony A, David M Kennedy, Elin J Waring, and Anne Morrison Piehl. 2001. "Problem-oriented policing, deterrence, and youth violence: An evaluation of Boston's Operation Ceasefire." Journal of Research in Crime and Delinquency 38:195-225.

Buerger, Michael E and Lorraine Green Mazerolle. 1998. "Third-party policing: A theoretical analysis of an emerging trend." Justice Quarterly 15:301-327.

Calderón, Gabriela, Gustavo Robles, Alberto Díaz-Cayeros, and Beatriz Magaloni. 2015. "The beheading of criminal organizations and the dynamics of violence in Mexico." Journal of Conflict Resolution 59:14551485 .

Cantor, David and Kenneth C Land. 1985. "Unemployment and crime rates in the post-World War II United States: A theoretical and empirical analysis." American Sociological Review pp. 317-332.

Dell, Melissa. 2015. "Trafficking networks and the Mexican Drug War." American Economic Review 105:1738-1779.

Dell, Melissa, Benjamin Feigenberg, and Kensuke Teshima. 2019. "The violent consequences of trade-induced worker displacement in mexico." American Economic Review: Insights 1:43-58.

Dickenson, Matthew. 2014. "The impact of leadership removal on Mexican drug trafficking organizations." Journal of Quantitative Criminology 30:651-676.

Grogger, Jeffrey. 2002. "The effects of civil gang injunctions on reported violent crime: Evidence from Los Angeles County." The Journal of Law and Economics 45:69-90.

Hainmueller, Jens, Jonathan Mummolo, and Yiqing Xu. 2019. "How much should we trust estimates from multiplicative interaction models? Simple tools to improve empirical practice." Political Analysis 27:163192.

Hill, Peter BE. 2003. The Japanese mafia: Yakuza, law, and the state. Oxford University Press.

Hill, Peter BE. 2004. "The changing face of the Yakuza." Global Crime 6:97-116.

Hirosue, Noboru. 2016. Yakuza ni naru riyu. Shinchosha.

Hoshino, Tetsuya and Takuma Kamada. 2020. "Third-Party Policing Approaches against Organized Crime: an Evaluation of the Yakuza Exclusion Ordinances." Journal of Quantitative Criminology .

Levi, Michael and Mike Maguire. 2004. "Reducing and preventing organised crime: An evidence-based critique." Crime, Law and Social Change 41:397-469.

Lindo, Jason M and María Padilla-Romo. 2018. "Kingpin approaches to fighting crime and community violence: Evidence from Mexico's drug war." Journal of health economics 58:253-268.

Mazerolle, Lorraine and Janet Ransley. 2006. Third party policing. Cambridge University Press. 
Milhaupt, Curtis J and Mark D West. 2000. "The dark side of private ordering: an institutional and empirical analysis of organized crime." The University of Chicago Law Review pp. 41-98.

Montalvo, Jose G and Marta Reynal-Querol. 2005. "Ethnic diversity and economic development." Journal of Development Economics 76:293-323.

National Police Agency. 2009. "Trends in the Yakuza (Boryokudan Josei)." .

National Police Agency. 2012. "White Paper on Police: Special Issue on the Yakuza (Keisatsu Hakusho)." .

National Police Agency. 2014a. "Trends in the Yakuza (Boryokudan Josei)." .

National Police Agency. 2014b. "White Paper on Police: Special Issue on the Yakuza (Keisatsu Hakusho)."

National Police Agency. 2015. "White Paper on Police: Special Issue on the Yakuza (Keisatsu Hakusho)." .

National Police Agency. 2018. "Trends in Organized Crime (Soshikihanzai Josei)." .

NHK. 2014. "The Yakuza: Where Have "Former Yakuza" Gone? (Boryokudan Kieta Ichimannin "Ridatsusha" ha Dokoe?)." .

NHK. 2018. “'Poor Yakuza' Has Become a Threat ('Hinkon Boryokudan’ ga Aratana Kyoui Ni).” .

Piehl, Anne Morrison, Suzanne J Cooper, Anthony A Braga, and David M Kennedy. 2003. "Testing for structural breaks in the evaluation of programs." Review of Economics and Statistics 85:550-558.

Ramseyer, J Mark. 2016. "Nuclear Power and the Mob: Extortion in Japan." Journal of Empirical Legal Studies 13:487-515.

Rubin, Donald B. 1987. Multiple imputation for nonresponse in surveys, volume . John Wiley \& Sons.

Sankei Shimbun. 2011. "Interview with Shinobu Tsukasa, the sixth leader of the Yamaguchi-Gumi (Rokudaime Tsukasa Shinobu Kumicho-Tandoku interview)." .

Wooldridge, Jeffrey M. 2010. Econometric analysis of cross section and panel data. MIT press. 


\section{ONLINE APPENDIX}

\section{A Robustness Check}

Now we demonstrate the robustness of our empirical results. All these results are reported in Table A1.

Estimation Method: Columns (1) and (2). We test the robustness to estimation methods. Column (1) reports the OLS estimation results. Regressors are no longer weighted by the prefecture population. Column (1) reports the WLS estimation result, using the GDP as weights. We obtain qualitatively similar results.

Alternative Identification Assumptions: Columns (3). We check the robustness of our main results under an alternative identification assumption. Instead of region-specific linear time trends, Column (3) controls for prefecture specific linear time trends, controlling for unobserved heterogeneity across prefectures that evolve over time linearly. The result remain qualitatively similar, but the coefficient for the interaction term between the YEOs and YCI is no longer statistically significant.

Alternative Definitions of YCI: Columns (4) to (7). We use alternative definitions of YCI. To compute YCI, we need to compute the share $s_{p g}$ of yakuza syndicate $g$ in prefecture $p$. In the main text, we assume that the members of yakuza syndicate $g$ are distributed proportionally to the population in prefecture $p$ where yakuza syndicate $g$ operates. For notational convenience, let $Y C I^{p o p}$ denote the YCI that we have used so far.

Now we recompute the share $s_{p g}$ based on alternative assumptions. First, suppose that the members of yakuza syndicate $g$ are distributed equally among all prefectures in which yakuza syndicate $g$ operates. Let $s_{p g}^{\text {naive }}$ denote the share that is calculated in this way, and let $Y C I_{p}^{\text {naive }}$ be the resulting YCI. Second, suppose that the members of yakuza syndicate $g$ are distributed proportionally to the population density of prefecture $p$ in which yakuza syndicate $g$ operates. Let $s_{p g}^{\text {density }}$ denote the share that is calculated in this way, and let $Y C I_{p}^{\text {density }}$ denote the resulting YCI. Using these two variants of YCI, we redo our estimation. As shown in Columns (4) and (5), our results are robust to the specifications.

Lastly, we use an alternative definition for the YCI. We redefine the YCI analogously to the Ethnic Polarization index (Montalvo and Reynal-Querol, 2005) for Column (6); we simply use the raw number of yakuza syndicates operating in each prefecture for the YCI for Column (7). As shown in the two columns, our results are qualitatively similar and robust.

Executive Order 13581: Column (8). Executive Order 13581, issued by the Obama administration, freezes the property of transnational criminal organizations, including the following four yakuza syndicates: Yamaguchi-gami, Sumiyoshi-kai, Inagawa-kai, and Kudo-kai. As this Executive 
Order was issued in April 2011, we add a treatment variable USEnforcement ${ }_{t}$, which is equal to 1 after April 2011 and 0 otherwise. We also add an interaction term $U S E n$ forcement $_{t} \times Y C I_{p}$, since the effect of the Executive Order may vary with the yakuza concentration. As shown in Column (8), the main effect of the YEOs remains significant while the interaction term between the YEOs and YCI does not. Furthermore, the main effect of the Executive Order is not statistically significant but its interaction with the YCI is.

Amendment of Anti-Yakuza Laws: Column (9). The Anti-Yakuza Laws, which are nationwide laws, were amended in October 2012. Since our estimation strategy is based on the DiD approach which exploits the prefectural variation, the amendment of the nationwide laws should not affect our results, and this is why we did not take into account.

Here we examine this assumption. Let the treatment dummy $A Y L_{t}$ be equal to 1 before the amendment and to 0 after the amendment. We add, to regression model (1), a non-interaction term $A Y L_{t}$ and an interaction term $A Y L_{t} \times Y C I_{p}^{p o p}$. Either term is insignificant but the two elements of interest, $Y E O_{p t}$ and $Y E O_{p t} \times Y C I_{p}^{p o p}$, remain significant.

Tohoku Earthquake: Column (10). Japan experienced the Tohoku Earthquake on March 11, 2011. It is often said that yakuza members engaged in business in the affected areas after the earthquake. For example, some of them participated in the repair of nuclear reactors (Ramseyer, 2016) and in the restoration of the affected areas. These economic opportunities might affect yakuza activities. A simple way to eliminate potential effects of the earthquake is to exclude prefectures that were affected by this earthquake (i.e., Miyagi, Iwate, Fukushima, Ibaraki, Tochigi, Chiba, and Kanagawa) from our dataset. Even using this subsample, we still obtain qualitatively the same results. 


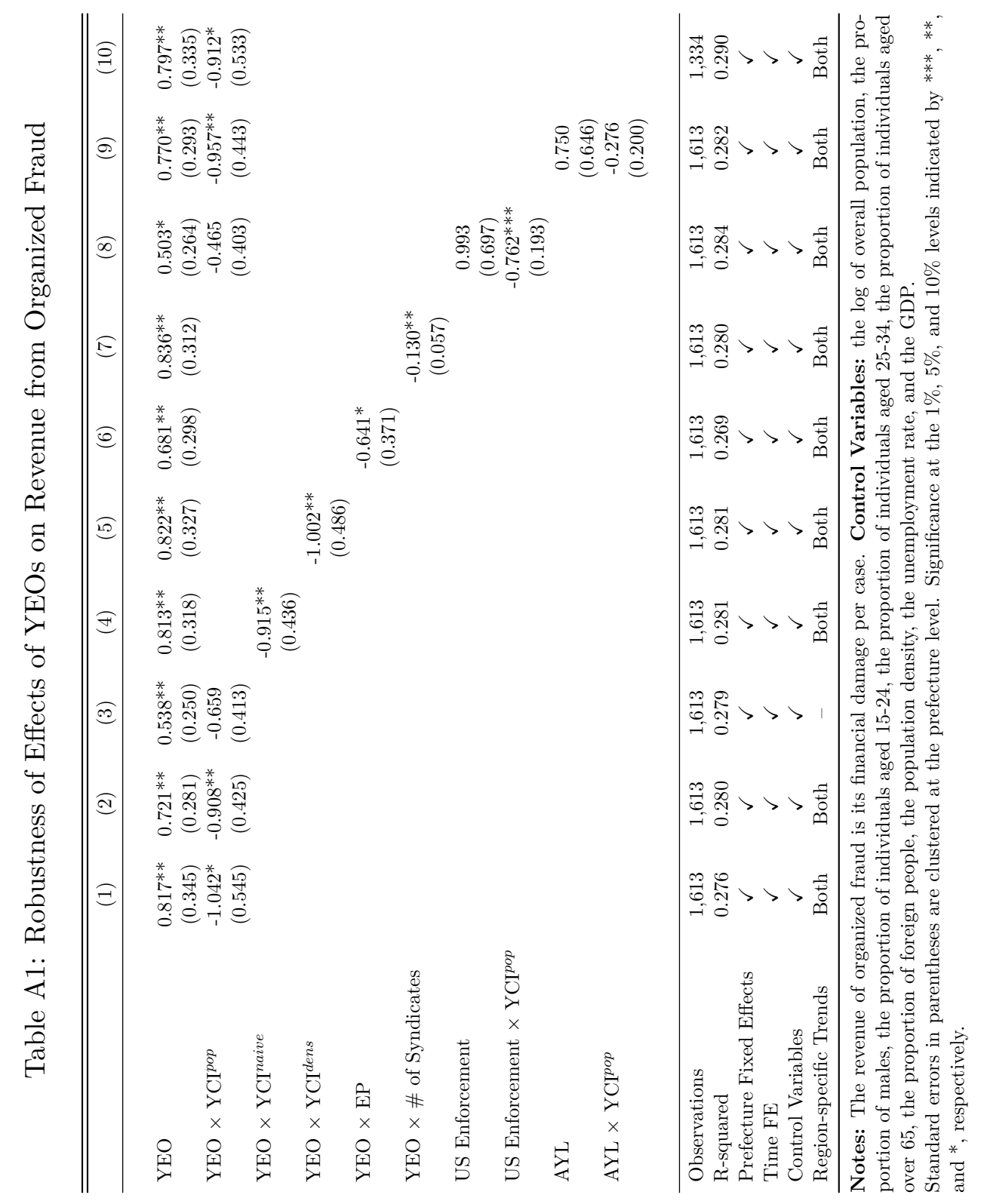




\section{B Alternative Channels for the Heterogeneity of the YEO Effect by YCI}

In the main text, we have shown that the YEO effects are stronger in areas with higher YCI, and interpreted this heterogeneity as a result of strategic interaction between yakuza syndicates. Here, we assess alternative channels for the heterogeneity.

The first alternative channel supposes that illegal markets in more yakuza-concentrated areas are more profitable. Since yakuza members have better illegal economic opportunities in such areas, they are less likely to resign from their syndicates and thus current and former yakuza members are less likely to engage in organized fraud. We indirectly assess this channel by looking at proxies for illegal markets, the number of the total arrests (not restricted to yakuza members) for one of the following: the use or distribution of methamphetamine per 100,000 inhabitants; ${ }^{11}$ prostitution per 100,000 inhabitants; and gun-related incidents per 100,000 inhabitants. That is, we regress the YCI on these measures, using the 2009 data. If the illegal market channel explains the heterogeneity in the YEOs' effects, we should observe higher arrest rates for these crimes in more yakuza-concentrated areas. As in Table A2, however, we find no statistically significant relevance.

The second alternative channel supposes that the enforcement level on yakuza is lower in prefectures with lower concentration of yakuza syndicates. We indirectly assess this channel by regressing the YCI on the number of police officers per 1,000 residents (from the 2009 data). If the policing channel explains the heterogeneity in the YEOs' effects, we should observe that higher presence of police officers is significantly related with lower concentration of yakuza syndicates. As in Table A2, however, we find no statistically significant relevance.

Lastly, our interpretation may be confounded with other prefecture-level characteristics that may be correlated with YCI. The lower YEOs' effectiveness in higher YCI areas could be because of regional differences in economic conditions. For instance, if prefectures with higher YCI are relatively poor regions, there can be fewer criminal opportunities in these regions, as suggested in the criminology literature (Cantor and Land, 1985). To assess this possibility, we regress the YCI on the GDP and welfare recipients per 1,000 residents (from the 2009 data). We also examine the relationship between YCI and other covariates used in the main analysis. As in Table A2, however, we find no statistically significant relevance. Furthermore, none of the coefficients for observed covariates, except for the ones of the size of population and of the proportions of foreignborn individuals, are statistically significant. The result provides suggestive evidence that these alternative channels explain the heterogeneous effect of the YEO by YCI.

\footnotetext{
${ }^{11}$ Methamphetamine is an illegal drug that is most frequently abused in Japan. In 2008, $77 \%$ of all drug-related arrests is related to methamphetamine. Yakuza syndicates are largely involved in smuggling and distributing it, earning a considerable amount of money.
} 
Table A2: Assessment of Alternative Channels for YCI

\begin{tabular}{|c|c|c|c|c|c|}
\hline Dependent Variable: YCI & (1) & $(2)$ & $(3)$ & (4) & $(5)$ \\
\hline In Methamphetamine Arrests per 100,000 & & $\begin{array}{c}0.124 \\
(0.093)\end{array}$ & & & \\
\hline ln Prostitution Arrests per 100,000 & & & $\begin{array}{c}0.089 \\
(0.153)\end{array}$ & & \\
\hline ln Gun Incident per 100,000 & & & & $\begin{array}{l}-0.053 \\
(0.071)\end{array}$ & \\
\hline ln \# of Police Officers per 1,000 & & & & & $\begin{array}{c}-0.162 \\
(0.560)\end{array}$ \\
\hline GDP & $\begin{array}{c}0.002 \\
(0.004)\end{array}$ & $\begin{array}{c}0.003 \\
(0.004)\end{array}$ & $\begin{array}{c}0.001 \\
(0.005)\end{array}$ & $\begin{array}{c}0.003 \\
(0.005)\end{array}$ & $\begin{array}{c}0.004 \\
(0.006)\end{array}$ \\
\hline Welfare Recipients per 1,000 & $\begin{array}{c}0.006 \\
(0.012)\end{array}$ & $\begin{array}{c}0.003 \\
(0.010)\end{array}$ & $\begin{array}{c}0.005 \\
(0.011)\end{array}$ & $\begin{array}{c}0.008 \\
(0.013)\end{array}$ & $\begin{array}{c}0.007 \\
(0.014)\end{array}$ \\
\hline ln Population & $\begin{array}{c}0.227^{* *} \\
(0.109)\end{array}$ & $\begin{array}{c}0.215^{* *} \\
(0.099)\end{array}$ & $\begin{array}{c}0.223^{*} \\
(0.113)\end{array}$ & $\begin{array}{c}0.203 \\
(0.122)\end{array}$ & $\begin{array}{c}0.211 \\
(0.137)\end{array}$ \\
\hline Proportions of Males & $\begin{array}{c}18.324 \\
(16.237)\end{array}$ & $\begin{array}{c}20.499 \\
(15.070)\end{array}$ & $\begin{array}{c}17.590 \\
(15.354)\end{array}$ & $\begin{array}{c}19.707 \\
(16.709)\end{array}$ & $\begin{array}{c}17.075 \\
(15.277)\end{array}$ \\
\hline Proportions of Aged 15-24 & $\begin{array}{c}12.470 \\
(14.019)\end{array}$ & $\begin{array}{c}15.046 \\
(13.355)\end{array}$ & $\begin{array}{c}11.431 \\
(13.789)\end{array}$ & $\begin{array}{c}12.074 \\
(14.096)\end{array}$ & $\begin{array}{c}12.247 \\
(13.949)\end{array}$ \\
\hline Proportions of Aged 25-34 & $\begin{array}{c}3.233 \\
(12.253)\end{array}$ & $\begin{array}{c}2.780 \\
(11.951)\end{array}$ & $\begin{array}{c}3.393 \\
(12.534)\end{array}$ & $\begin{array}{c}4.970 \\
(12.714)\end{array}$ & $\begin{array}{c}3.876 \\
(13.197)\end{array}$ \\
\hline Proportions of Aged 65 and Over & $\begin{array}{l}10.556 \\
(8.087)\end{array}$ & $\begin{array}{l}12.096 \\
(8.024)\end{array}$ & $\begin{array}{l}10.506 \\
(7.984)\end{array}$ & $\begin{array}{l}10.912 \\
(8.095)\end{array}$ & $\begin{array}{l}10.538 \\
(8.052)\end{array}$ \\
\hline Proportions of Foreign-born Individuals & $\begin{array}{c}-19.650^{* *} \\
(7.983)\end{array}$ & $\begin{array}{c}-24.512^{* *} \\
(10.101)\end{array}$ & $\begin{array}{c}-18.795^{* *} \\
(7.517)\end{array}$ & $\begin{array}{c}-20.473^{* *} \\
(8.501)\end{array}$ & $\begin{array}{c}-18.228^{*} \\
(9.456)\end{array}$ \\
\hline Population Density & $\begin{array}{l}-0.000 \\
(0.000)\end{array}$ & $\begin{array}{c}0.000 \\
(0.000) \\
\end{array}$ & $\begin{array}{c}0.000 \\
(0.000) \\
\end{array}$ & $\begin{array}{l}-0.000 \\
(0.000)\end{array}$ & $\begin{array}{c}-0.000 \\
(0.000)\end{array}$ \\
\hline Observations & 47 & 47 & 47 & 46 & 47 \\
\hline R-squared & 0.404 & 0.438 & 0.412 & 0.408 & 0.406 \\
\hline
\end{tabular}

Notes: Standard error: Robust standard errors. Estimator: weighted least squares, using the prefectural populations as weights.

Significance at the $1 \%, 5 \%$, and $10 \%$ levels indicated by $* * *, * *$, and $*$, respectively. 


\section{YEO's Effects on Total Financial Damage by Organized Fraud and on Number of Organized Fraud Cases}

This section examines the YEOs' effects on the total financial damage by organized fraud and the number of organized fraud cases per 100,000 residents. Recall that in the main text, we have studied the effects on the revenue of organized fraud per case. This analysis allow us to better understand whether our result in the main text is driven by the increase in the number of cases. As shown in Table A3, the YEOs increase the total financial damages but not the number of cases.

Table A3: YEO's Effects on Total Financial Damage by Organized Fraud and on Number of Organized Fraud Cases

\begin{tabular}{|c|c|c|c|c|}
\hline \multicolumn{5}{|c|}{ Dependent Variable: In Financial Damage Due to Organized Fraud } \\
\hline Panel A: & $(1)$ & $(2)$ & $(3)$ & $(4)$ \\
\hline YEO & $\begin{array}{c}0.861^{* *} \\
(0.364)\end{array}$ & $\begin{array}{c}0.901^{* *} \\
(0.363)\end{array}$ & $\begin{array}{c}0.900 * * \\
(0.365)\end{array}$ & $\begin{array}{c}0.832^{* *} \\
(0.369)\end{array}$ \\
\hline $\mathrm{YEO} \times \mathrm{YCI}$ & $\begin{array}{c}-1.023^{*} \\
(0.518)\end{array}$ & $\begin{array}{c}-1.137^{* *} \\
(0.520)\end{array}$ & $\begin{array}{c}-1.136^{* *} \\
(0.518)\end{array}$ & $\begin{array}{l}-0.877 \\
(0.551)\end{array}$ \\
\hline R-squared & 0.762 & 0.764 & 0.748 & 0.768 \\
\hline \multicolumn{5}{|c|}{ Dependent Variable: ln Organized Fraud Case per 100,000 Residents } \\
\hline Panel B: & $(1)$ & $(2)$ & $(3)$ & $(4)$ \\
\hline YEO & $\begin{array}{c}0.134 \\
(0.192)\end{array}$ & $\begin{array}{c}0.120 \\
(0.191)\end{array}$ & $\begin{array}{c}0.127 \\
(0.197)\end{array}$ & $\begin{array}{c}0.011 \\
(0.177)\end{array}$ \\
\hline $\mathrm{YEO} \times \mathrm{YCI}$ & $\begin{array}{l}-0.126 \\
(0.251)\end{array}$ & $\begin{array}{c}-0.162 \\
(0.263)\end{array}$ & $\begin{array}{l}-0.177 \\
(0.260)\end{array}$ & $\begin{array}{c}0.166 \\
(0.255)\end{array}$ \\
\hline R-squared & 0.671 & 0.684 & 0.697 & 0.697 \\
\hline Observations & 1,613 & 1,613 & 1,613 & 1,613 \\
\hline Control Variables & $\checkmark$ & $\checkmark$ & $\checkmark$ & $\checkmark$ \\
\hline Prefecture Fixed Effects & $\checkmark$ & $\checkmark$ & $\checkmark$ & $\checkmark$ \\
\hline Month $\times$ Year Fixed Effects & $\checkmark$ & $\checkmark$ & $\checkmark$ & $\checkmark$ \\
\hline Region-specific Trends & No & Linear & Quadratic & Both \\
\hline
\end{tabular}

Control Variables: the log of overall population, the proportion of males, the proportion of individuals aged 15-24, the proportion of individuals aged 25-34, the proportion of individuals aged over 65 , the proportion of foreign people, the population density, the unemployment rate, and the GDP.

Standard errors in parentheses are clustered at the prefecture level. Significance at the $1 \%, 5 \%$, and $10 \%$ levels indicated by $* * *, * *$, and $*$, respectively. 


\section{Designated Yakuza Syndicates}

Under the Anti-Yakuza Laws, twenty-one yakuza syndicates are "designated" during the period of the study. The criteria for the designation is that a yakuza syndicate has a hierarchical organizational structure, that its members use violence to earn money, and that its members have criminal records. Table A4 lists up all the designated yakuza syndicates. \#pref. of influence is the number of prefectures in which the particular yakuza syndicate operates. ${ }^{12}$

Table A4: Designated Yakuza Syndicates

\begin{tabular}{lr||lr}
\hline yakuza syndicate & \#pref. of influence & yakuza syndicate & \#pref. of influence \\
\hline Yamaguchi-gumi & 45 & Shinwa-kai & 1 \\
Inagawa-kai & 19 & Sōai-kai & 2 \\
Sumiyoshi-kai & 18 & Kyokudō-kai & 5 \\
Kudō-kai & 3 & Taishū-kai & 1 \\
Kyokuryu-kai & 1 & Sakaume-gumi & 1 \\
Aizukotetsu-kai & 2 & Kyokutō-kai & 15 \\
Kyōsei-kai & 1 & Azuma-gumi & 1 \\
Gōda-ikka & 3 & Matsuba-kai & 10 \\
Kozakura-ikka & 1 & Fukuhaku-kai & 4 \\
Asano-gumi & 2 & Namikawamutsumi-kai & 6 \\
Dōjin-kai & 4 & & \\
\hline
\end{tabular}

\footnotetext{
${ }^{12}$ There were twenty-two designated yakuza syndicates, but in 2011 , two of them, both of which operated only in Okinawa, merged.
} 


\section{E Summary Statistics of Outcome and Control Variables for Prefecture- Level Analysis}

Table A5: Summary Statistics of Outcome and Control Variables for Prefecture-Level Analysis

\begin{tabular}{lrr}
\hline \hline & Mean & Std. Dev. \\
\hline Revenue from Organized Fraud (million) & 4.249 & 5.125 \\
Yakuza Rates & 43.080 & 19.320 \\
Violent Crime Rates & 0.775 & 0.329 \\
Property Crime Rates & 10.324 & 5.051 \\
Bankruptcy & 0.597 & 0.338 \\
Debt (million) & 4412.198 & 18593.94 \\
Proportion of Males & 0.482 & 0.010 \\
Proportion Aged 15-24 & 0.096 & 0.008 \\
Proportion Aged 25-34 & 0.112 & 0.012 \\
Proportion Aged 65+ & 0.251 & 0.028 \\
Proportion of Foreign People & 0.012 & 0.007 \\
Population & 2717541 & 2644111 \\
Population Density & 653.677 & 1159.631 \\
Welfare Recipients per 1,000 Inhabitants & 14.065 & 7.083 \\
GDP (trillion) & 11.253 & 15.594 \\
\hline
\end{tabular}

Notes: The revenue of organized fraud is its financial damage of organized fraud per case. The yakuza rate is the number of yakuza members per 100,000 inhabitants. Data Sources: the yakuza data from prefectural police departments; the crime data (fraud, overall violent and property crime) from the NPA; the bankruptcy and debt data from the business mutual aid association research and investigation reports. the control variables from e-Stat. 


\section{F Summary Statistics of Outcome and Control Variables for Ward- Level Analysis}

Table A6: Summary Statistics of Outcome and Control Variables for Ward-level Analysis

\begin{tabular}{lrr}
\hline \hline & Mean & Std. Dev. \\
\hline Fraud & 14.857 & 9.497 \\
Extortion & 4.466 & 4.125 \\
Methamphetamine & 23.316 & 19.123 \\
Overall Property Crime & 22.256 & 14.733 \\
Overall Violent Crime & 30.992 & 21.441 \\
Proportion of Males & 0.493 & 0.013 \\
Average Age & 44.078 & 1.097 \\
Proportion Aged 65+ & 0.200 & 0.025 \\
Proportion of Foreign Residents & 0.046 & 0.025 \\
Welfare Recipients per 1,000 Inhabitants & 16.887 & 8.293 \\
Taxable Income (billion) & 544.000 & 446.000 \\
\hline
\end{tabular}

Notes: Outcomes are the numbers of yakuza arrests. Data Sources: Data on yakuza arrests are obtained from the Tokyo Metropolitan Police Department; other control variables are obtained from e-Stat. 